Check for updates

Cite this: Mater. Adv., 2022, 3, 2291

Received 17th October 2021, Accepted 9th January 2022

DOI: 10.1039/d1ma00960e

rsc.li/materials-advances

\section{Challenges and opportunities of silk protein hydrogels in biomedical applications}

\author{
Junwei Liu, (D) ${ }^{\text {abc }}$ Xiaodong Ge, (D) ${ }^{d}$ Liang Liu, (D) ${ }^{\text {ac }}$ Wei Xu (D) ${ }^{b c}$ and \\ Rong Shao (D)*ac
}

In the context of this era of complementary interdisciplinary advances, the design and preparation of hydrogel materials has been a hot avenue of research for a variety of applications. Silk proteins are an important natural resource for the preparation of silk-based hydrogels: their remarkable biological characteristics give them an important position in the field of biomedicine. The functional utilization of silk protein can not only contribute great added value to natural resources, but also meets the needs of green production, fully embodying the significant advantages of the 'atomic economization' manufacturing industry. This review examines the relationship between silk protein structure-performance-function, systematically summarizes the latest research in the preparation of silk protein hydrogel materials, analyzes the important applications of silk protein hydrogel materials in biomedical fields such as tissue engineering, controlled drug release, injectable hydrogels, and intelligent monitoring and sensing, and finally evaluates their potential value as a new type of biomaterial in future clinical medical applications. The introduction of genetic engineering and nanotechnology has brought huge challenges and unlimited opportunities to scientific researchers. As one of the most widely researched biomaterials, the developmental research of silk protein hydrogel materials has been continuously expanded.
${ }^{a}$ School of Chemistry and Chemical Engineering, Yancheng Institute of Technology, Yancheng 224051, P. R. China. E-mail: sr@ycit.cn

${ }^{b}$ School of Marine and Bioengineering, Yancheng Institute of Technology, Yancheng 224051, P. R. China

c Jiangsu Key Laboratory of Biochemistry and Biotechnology of Marine Wetland, Yancheng Institute of Technology, Yancheng 224051, P. R. China

${ }^{d}$ College of Food Science, Fujian Agriculture and Forestry University, Fuzhou 350002, P. R. China

\section{Introduction}

The use of silk has thousands of years of history, and its rich output, excellent mechanical properties, color sense luster, and soft and delicate feel cause it to be known as the 'Queen of Fibers'. The functional properties and practical applications of silk fiber are too numerous to count, especially as a natural green protein material that has received extensive attention in the field of biomedicine. ${ }^{1}$ Silk fiber plays a pivotal role in biomedical materials, similar to biomaterials such as chitosan, polylactic acid and collagen. The acquisition of natural silk

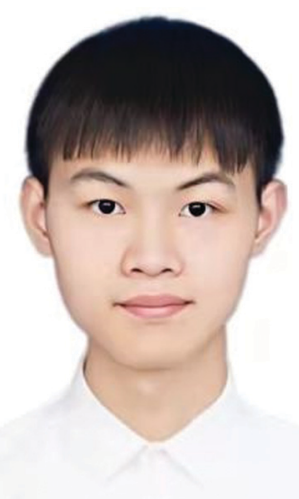

Junwei Liu
Junwei Liu is currently pursuing a master's degree in the School of Chemistry and Chemical Engineering, Yancheng Institute of Technology (China), under the guidance of Prof. Rong Shao. His current research focuses on the development and design of multifunctional silk protein hydrogels for controlled drug release.

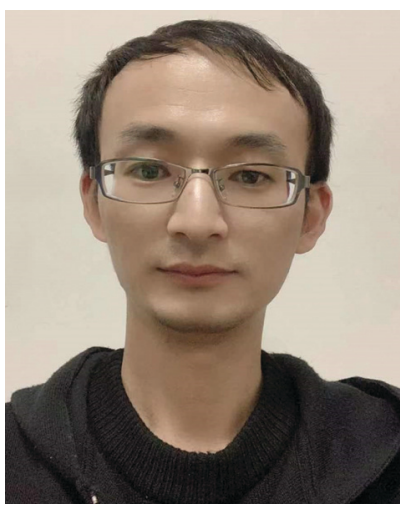

Xiaodong Ge
Xiaodong Ge is currently pursuing his PhD degree in the College of Food Science of Fujian Agriculture and Forestry University. His current research focuses on the research and application of the functionalization of bioactive substances. 
fiber requires the production and maturation of mulberry silkworms, silk spinning and cocooning, and artificial stripping of raw silk from cocoons. A mulberry cocoon is a fibrous composite material with a multilayer network structure mainly composed of approximately $70 \%$ silk fibroin and $30 \%$ sericin. $^{2}$ Silk fibroin, the most important component of silk fiber, has become a focus of intense current research because of its excellent biocompatibility, good permeability, nontoxicity, non-irritation, and superior mechanical properties. ${ }^{3-5}$ Among the many silk fiber-based biomaterials that have been developed, silk protein hydrogels derived from silk have been favored by researchers in the biomedical field due to their excellent biological properties, internal structures such as extracellular matrices and diversified gel methods. However, basic research on and practical applications of silk fibers are still in their infancy and the formation mechanisms of their three-dimensional structure and functional units of biological activity require further study. ${ }^{6}$ With continuous in-depth research on silk fibers, related problems have been gradually solved and research on new products, biological activity and

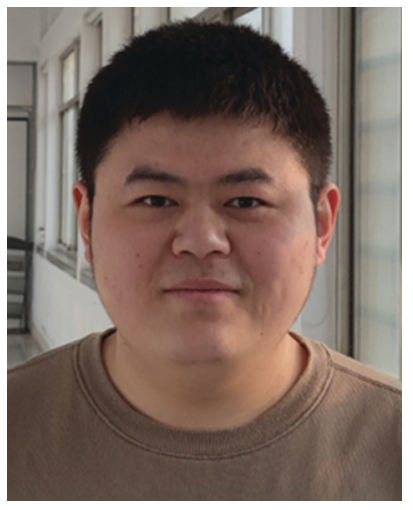

Liang Liu received his PhD from the Changchun Institute of Applied Chemistry Chinese Academy of Sciences in 2019. His doctoral research focuses on stimuliresponsive polymeric hydrogels for controlled drug release and tissue engineering. After obtaining his PhD, he started working with Prof. Rong Shao at the Yancheng Institute of Technology. His present research interest focuses on developing functional nanoparticles based on natural polymers for antibacterial therapy. functional materials based on silk fibers will be greatly accelerated. ${ }^{7,8}$ Research on the biocompatibility, stability, alternative mechanical properties and drug-carrying systems of silk protein hydrogels will play an important role in further improving the scale and benefits of treatment, reducing costs and continuously improving human health. ${ }^{9}$

In recent years, research on hydrogel materials has achieved breakthrough developments, penetrating many fields such as flexible wearable electronic devices, tissue engineering, nanosensors, bionic materials and regenerative medicine. However, different disciplines have diverse requirements for the physical and chemical properties of hydrogel materials and functional hydrogels and their composite materials still require in depth study to meet diverse interdisciplinary needs. ${ }^{10-13}$ Hydrogels have become one of the most widely studied natural biomaterial substrates in the field of biomedicine. ${ }^{14}$ Hydrogels are typical polymers that are rich in water molecules and have a threedimensional network cross-linked structure. They have the ability to absorb a large amount of water, swell, and maintain stability in water for a long time. ${ }^{15}$ The hydrophilicity of the polymer molecular chain can promote interaction between the chain and water molecules, and the cross-linked structure can ensure that the hydrogel network will not dissolve. Hydrogel materials generally have a porous internal structure and small molecules can diffuse well within and outside of gels. ${ }^{16}$ Through the design of the polymer chain structure and the introduction of different additives, hydrogels can be given various properties such as high mechanical strength, degradability and stimulus responsiveness. ${ }^{16,17}$ Therefore, hydrogels have extraordinary application potential in many fields such as water locking and moisturizing, sewage treatment, and biomedical and electronic sensing. ${ }^{18-21}$ Compared with chemically synthesized hydrogels, natural polymer hydrogels have particular natural characteristics and good biocompatibility and are highly similar to natural tissue structures. They have significant application advantages in the fields of tissue engineering and regenerative medicine and thus have attracted much attention. ${ }^{22,23}$

As a typical representative of natural polymers, silk protein has now been developed into a novel advanced biomaterial. Silk

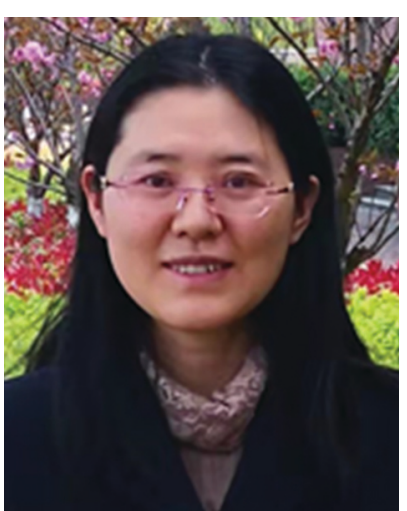

Wei Xu
Prof. Wei Xu was born in 1976 and educated at Nanjing Tech University where she gained her PhD. She was invited as a visiting scholar to the Department of Chemical and Biomolecular Engineering at The Ohio State University for one year. She is currently mainly engaged in research work in the field of the application of renewable resources by biotechnology and enzyme

engineering.

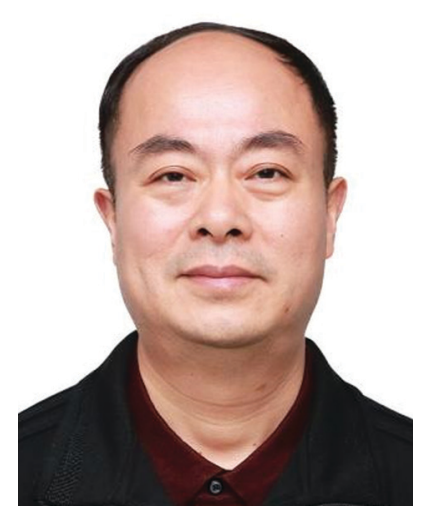

Rong Shao
Prof. Rong Shao graduated from Nanjing Tech University with a doctorate degree in engineering in 2000, majoring in chemical engineering. He was promoted to the position of professor in 2010 and served as vice-chancellor of the Yancheng Institute of Technology (YCIT) in 2012. He is now the leader of YCIT's Bioengineering, which is a Provincial Key Constructive Discipline and serves as the director of Jiangsu Key Laboratory of Biochemistry and Biotechnology of Marine Wetland. He has long been engaged in related research in biochemical engineering and interdisciplinary fields. 


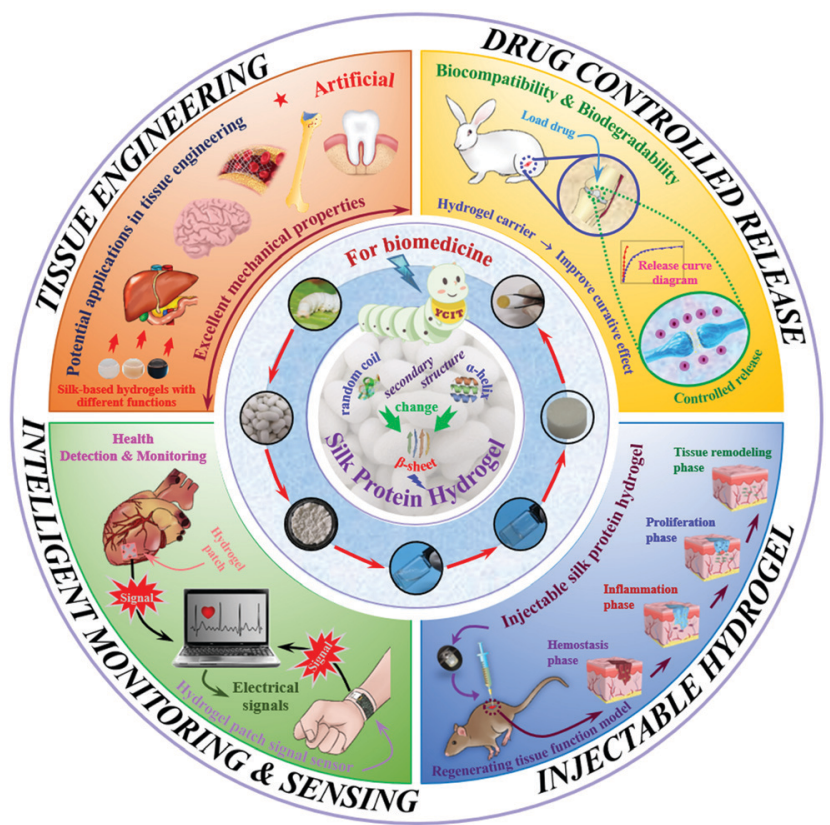

Fig. 1 Schematic diagram of the biomedical applications of silk protein hydrogels.

protein aqueous solutions are obtained after dissolving silk fibers, which can then be gelled to form silk protein hydrogels through various physical and chemical or biological means. The typical transformation process of a hydrogel based on silk protein is presented in Fig. 1. And its biomedical utilities are also summarized, including tissue engineering, controlled drug release, injectable hydrogel construction and intelligent monitoring/sensing. The preparation method and process flow are simple and easy to operate, and large-scale fixed production can be realized. In addition, silk protein hydrogels have a controllable molecular structure, excellent mechanical properties and biological properties and are expected to become advanced model biomedical materials commonly used in the biomedical field. With the unremitting efforts of many scientific researchers, silk protein hydrogels and their composite hydrogel materials have been endowed with unique and excellent properties, such as injectability, high elasticity, high mechanical strength and environmental sensitivity, and have achieved a number of satisfactory research results. ${ }^{1424-28}$ However, there is always a weakness in the mechanical properties of materials, such as, how to improve their mechanical properties to the greatest extent, urgently requiring further exploration of regulation and optimization strategies. As an increasing number of disciplines intersect, more industrialized advanced hydrogel materials have been developed and applied.

Against the strategic background of sustainable development, exploration in the field of biomaterials has been continuously promoted. Compared with synthetic materials, researchers are paying increased attention to natural biomaterials. ${ }^{29,30}$ The continuous innovation and development of silk protein hydrogel materials, as the core carrier of biomimetic and regeneration, have greatly advanced the development process of biomedicine, created huge social and economic benefits, and opened up a new path for the development of global medical practices. This review mainly focuses on the preparation of silk-proteincomposite hydrogels, their structure-performance-function relationships and applications in biomedicine, providing a useful reference for further enhancing the natural silk industry and promoting its biomedical and clinical applications. Besides, the current dilemmas and future prospects of silk protein hydrogels are also involved and elaborated in this review for its readers to better comprehend this area.

\section{Microstructure and properties of silk protein}

\subsection{Structural composition and molecular conformation}

The structure and properties of nanoscale silk fibers prepared from cocoon silks of different silkworm species are quite different. This research mainly explores the structure and properties of silkworm and tussah cocoon silk. Tussah silk fiber's primary structure contains a special arginine-glycineaspartic acid (Arg-Gly-Asp, RGD) sequence distributed in a variety of extracellular matrices, which can effectively promote the adhesion and growth of cells on biological materials (Fig. 2, left). ${ }^{31-35}$ However, compared with mulberry silk, tussah silk has disadvantages: preparation of its silk protein aqueous solution is difficult and it possesses poor processing and molding performance, greatly limiting research on and applications of tussah silk fiber-based biomaterials. ${ }^{36}$ At present, the most widely used material is undoubtedly silk nanofibers derived from silkworms (Fig. 2, right). Silk nanofibers mainly refer to degummed silk protein components, accounting for approximately $70-75 \%$ of silk and containing 18 different amino acids. The sequence Gly-Ala-Gly-Ala-Gly-X, with X representing a Ser residue or containing Ser residues of other amino acid residues such as GAGAGS, GAGAGA, and GAGAGY, constitutes the main body of repeated sequences which, through intermolecular hydrogen bonding and hydrophobic interaction forces forms a protein secondary structure and then forms the crystalline region of the hydrophobic polypeptide molecule. ${ }^{31,37}$

In recent years, the molecular biology of silk protein has been increasingly refined. It has been confirmed that silk protein is composed of two polypeptide chains of the light chain (L chain, $\sim 26 \mathrm{kDa}$ ) and heavy chain ( $\mathrm{H}$ chain, $\sim 340 \mathrm{kDa}$ ) through disulfide bonds. A complete silk protein molecule is formed by binding to glycoprotein P25 $(\sim 24 \mathrm{kDa})$ through noncovalent interactions such as hydrophobic bonds. ${ }^{38,39}$ GAGAGS repetitive sequences mostly appear in the $\mathrm{H}$ chain and easily form a stable and regular $\beta$-sheet conformation, the main component of the crystalline region of silk fibers. In contrast, the irregular and nonrepetitive polypeptide fragments of the $\mathrm{L}$ chain tend to form amorphous regions, resulting in poor structural stability. ${ }^{40}$ Silk protein has two typical conformations, namely, water-soluble structure type I (Silk I) and $\beta$-sheetcontaining type II (Silk II). Different crystal types are arranged alternately and associate to form a fibrous structure. ${ }^{41}$ Among 

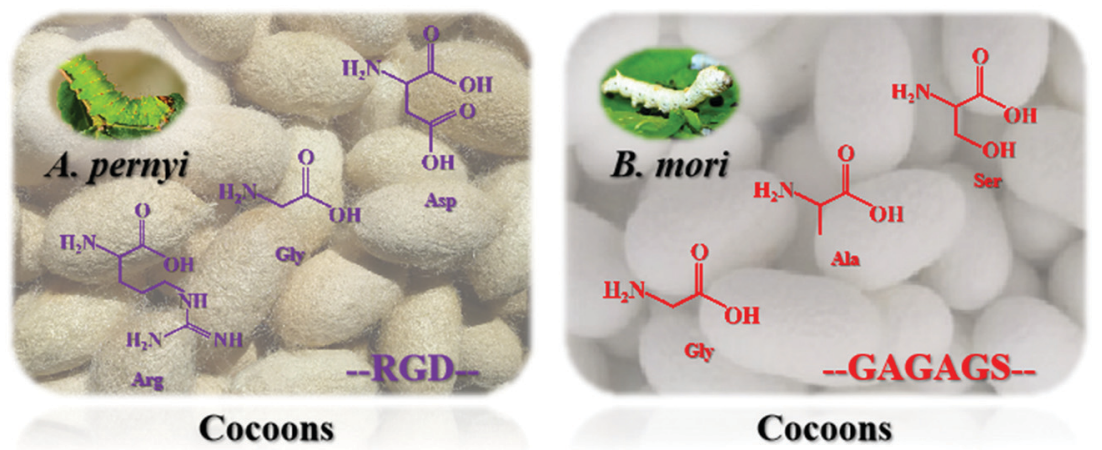

Fig. 2 The basic structure of tussah and mulberry silkworm cocoons. The primary structure of the tussah cocoon contains a special arginine-glycineaspartic acid (RGD) sequence which can effectively promote the adhesion and growth of cells on biological materials and is widely distributed in a variety of extracellular matrices. The silkworm cocoon contains 18 kinds of amino acids, and the main body is the repetitive sequence GAGAGS forming the secondary structure of the protein through intermolecular hydrogen bonds and hydrophobic forces and then forming the crystalline region of the hydrophobic polypeptide molecule.

these, the conformation of Silk I is mainly $\alpha$-helix and random coil while the conformation of Silk II is anti-parallel $\beta$-sheets. ${ }^{42,43}$ Under specific processing conditions, the two can be transformed into each other through physical and chemical means such as ultrasound, shear force, energization and $\mathrm{pH}$ adjustment, and their macroscopic appearance is mutual transformation between different existing forms (solution, gel, film, etc.). With the loss of water from the solution, they can also transform irreversibly. ${ }^{44-47}$

\subsection{Structure-performance-function relationship}

The size of the complex nanostructures of silk fibers can range from a few nanometers to hundreds of nanometers, a ubiquitous trait of animal silk endowing silk fibers with unique mechanical properties and flexibility. At the same time, natural biological properties make silk fibers different from synthetic fibers and other natural engineering fiber materials. ${ }^{48}$ Some of the strengths and ductility of silk fiber analogs have different degrees of difference, and silk fibers can compensate for the inadequacy of their analogs. Their fortuitous combination of strength and ductility allows them to absorb much energy before fracture, exhibiting a unique natural flexibility and to a maximum extent reducing the embrittlement of silk fibers, demonstrating that silk proteins have excellent mechanical properties that can be exploited. ${ }^{49-52}$ Aramid fiber is a kind of poly-p-phenylene terephthalamide whose strength and modulus are significantly higher than those of silk and spider silk, but its ductility is very poor: less than one-tenth of silk. ${ }^{53}$ In contrast, the excellent mechanical properties of silk protein combined with its processability have led to their preparation into functional materials such as gels, scaffolds, sponges and films to be used in various fields and markets, and its future development prospects can be described as bright. ${ }^{54-57}$

A typical feature of silk protein is the existence of nanoscale pores or cracks, and the design of layered nanostructures can effectively reduce brittle-type damage to silk fiber, improving its flexibility. ${ }^{58}$ At the nanometer scale, the utilization of hydrogen bonds is maximized as much as possible so that the stick-slip of dissipated molecules can achieve the higher strength, stiffness and flexibility of large nanocrystals. ${ }^{59}$ The cellular performance of silk protein hydrogels has attracted much attention in the field of bioregenerative medicine. The three-dimensional network structure of silk protein hydrogels has a high permeability in the body, which is conducive to the internal and external circulation of nutrients, and can realize the material exchange with metabolites. It is suitable for the loading and delivery of various therapeutic cells. Therapeutic cells secrete growth factors and successfully act on external cells and tissues through the porous structure of silk protein hydrogels to achieve tissue repair. ${ }^{60}$ The use of catechol with tissue adhesion properties to modify the hydrogel, giving the hydrogel high bioadhesion, can promote rapid wound healing. ${ }^{61}$ Therefore, silk protein hydrogels have a certain ability to guide cell behavior. In addition, the hydrogel can also be loaded with necessary activity-inducing factors to regulate cell behavior. Feng et $a l^{62}$ developed a unique cell-permeable and injectable gelatin hydrogel, which is cross-linked by a weak and highly dynamic host-guest complex, which is more conducive to the interaction between cells and hydrogels. Therefore, silk protein hydrogels can be used for cell delivery, provide a threedimensional environment required for cell culture, and support cell adhesion, proliferation, and differentiation by means of mechanical property regulation, chemical modification, and biological functional modification.

The survival rule of nature requires that the general use of organic dyes should be avoided, so camouflaging structural color is generated through periodic pore arrangement, another interesting nanoscale pore structure in addition to the abovementioned typical fibrous nanofeatures. ${ }^{63}$ Compared with gelatin and chitosan, which have been widely used in the field of biomimetic materials and regenerative medicine, silk protein, a natural protein material, possesses the great advantages of excellent biocompatibility and controllable biodegradability. Combined with its adjustable mechanical properties and the low antigenicity of silk protein, the physiological safety of implantation in the body can be better guaranteed. ${ }^{64}$ In vitro enzyme degradation experiments have shown that various enzymes such as elastase, collagenase and actinomycin protease can degrade silk protein materials. ${ }^{65,66}$ The mechanism of degradation is mainly enzyme-catalyzed breakage of the silk 
protein molecular chain. Different silk treatment processes result in highly varying molecular weights for silk proteins, resulting in differences in the molecular chain breakage rate, which regulates its biodegradation performance.

\section{Silk protein hydrogel}

\subsection{Regenerated silk fibroin hydrogel}

Silk fibroin is a natural protein substance extracted from silk that is mainly synthesized and secreted by endothelial cells on the inner wall of the silkworm and is rich in 20 amino acids such as glycine (Gly), alanine (Ala) and serine (Ser). ${ }^{67}$ As a kind of natural polymer biomaterial, silk fibroin has the advantages of abundant sources, easy production and availability, good biocompatibility, low immunogenicity, and high safety performance. ${ }^{42,68}$ Research and application in the field of biomaterials has a long history. For example, silk fibers have been used as surgical sutures for hundreds of years due to their excellent properties. Silk fibroin hydrogels are an important macroscopic form of protein materials. They have flexibility and plasticity, are permeable to gas and some small molecular substances and are the preferred choice for the preparation of biological and medical materials such as wearable sensors, flexible electronic skin, cell culture scaffolds, enzyme immobilized carriers and drug slow-release carriers. ${ }^{69-73}$ Researchers continue to explore the mechanisms of formation of silk fibroin hydrogels and carry out modification studies, combining silk fibroin with biological enzymes, ${ }^{74}$ hyaluronic acid, ${ }^{75}$ gelatin, $^{76}$ drug particles ${ }^{77}$ and high molecular polymers ${ }^{78}$ to prepare silk fibroin composite hydrogels, and use technical means such as genetic engineering to obtain silk-based elastic hydrogels. ${ }^{79}$ While retaining the original excellent properties of silk fibroin hydrogel, they are endowed with excellent properties that broaden their application value. However, silk fibroin hydrogels are mainly suitable as soft tissue medical materials and their simple preparation method results in weaker gel performance, which needs to be strengthened and has no environmental responsiveness. $^{80}$ Therefore, improving the mechanical properties and functionality of the material is an important factor in the real practicality of silk fibroin hydrogel materials.

3.1.1. Preparation and characterization. The silk protein hydrogel is prepared from silk protein aqueous solutions through different gel methods. Among these, preparation from silk protein solution is a very mature method that has been continuously optimized. The conventional method here is to cut the cocoons or silk into degummed silk (such as in the sodium carbonate secondary boiling method) and then use different dissolution systems (lithium bromide solution is most commonly used) to dissolve the degummed silk, dialyze it with deionized water and concentrate it to obtain a stock solution of silk protein aqueous solution (Fig. 3). Researchers have compared different dissolution systems to explore and optimize the dissolution and aqueous solution preparation of silk protein to find a stable and efficient green channel preparation method. As shown in Table 1, silk protein aqueous solution is processed by concentration (or natural gel), heating and temperature control, ${ }^{81}$ ultrasonic vibration, ${ }^{82}$ vortex shear, ${ }^{83}$ electricity gel ${ }^{84}$ and acid (ionic liquid or surfactant) treatment, ${ }^{85}$ and the addition of cross-linking agents ${ }^{86-88}$ can transform the molecular conformation of silk protein from $\alpha$-helix and random coil to

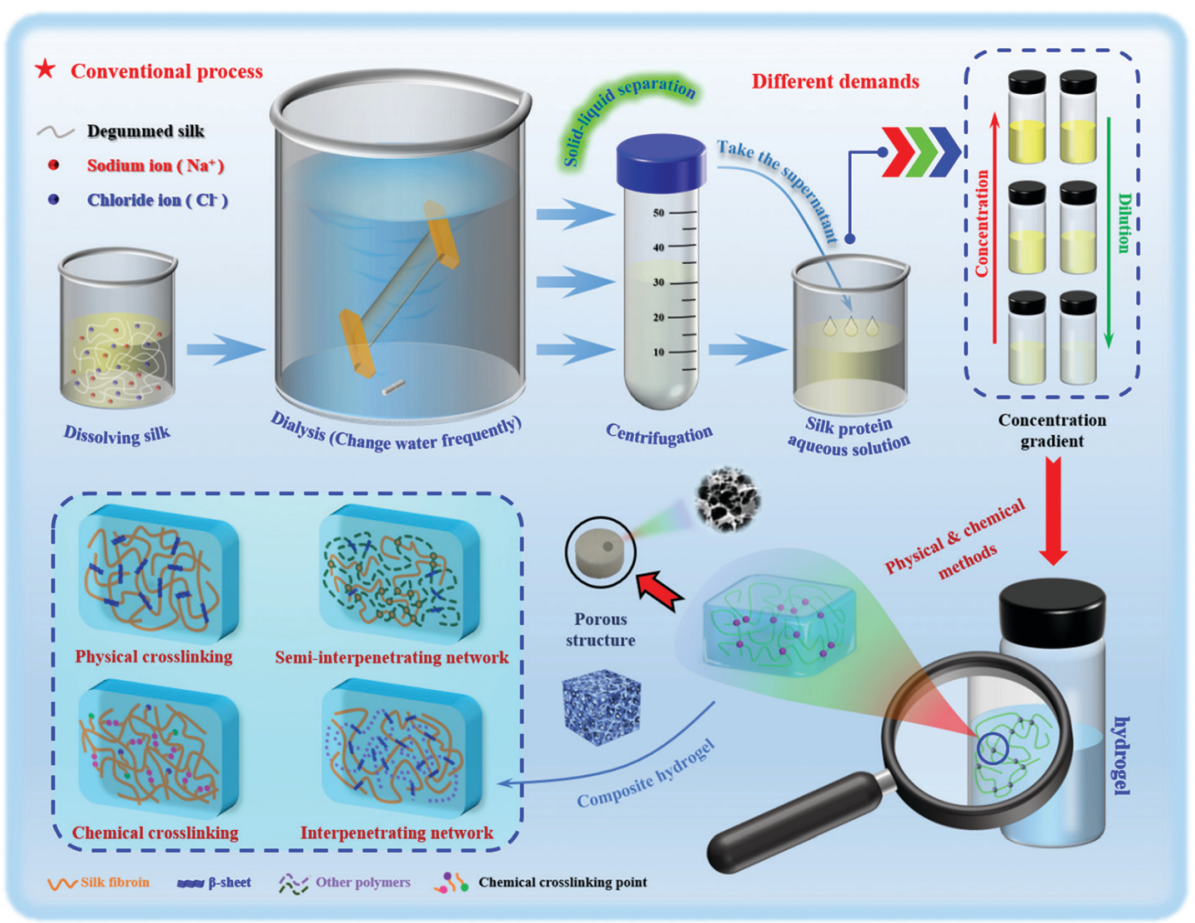

Fig. 3 Typical preparation procedure for silk protein hydrogels. 
Table 1 Advantages and disadvantages of the different preparation methods of silk protein hydrogels

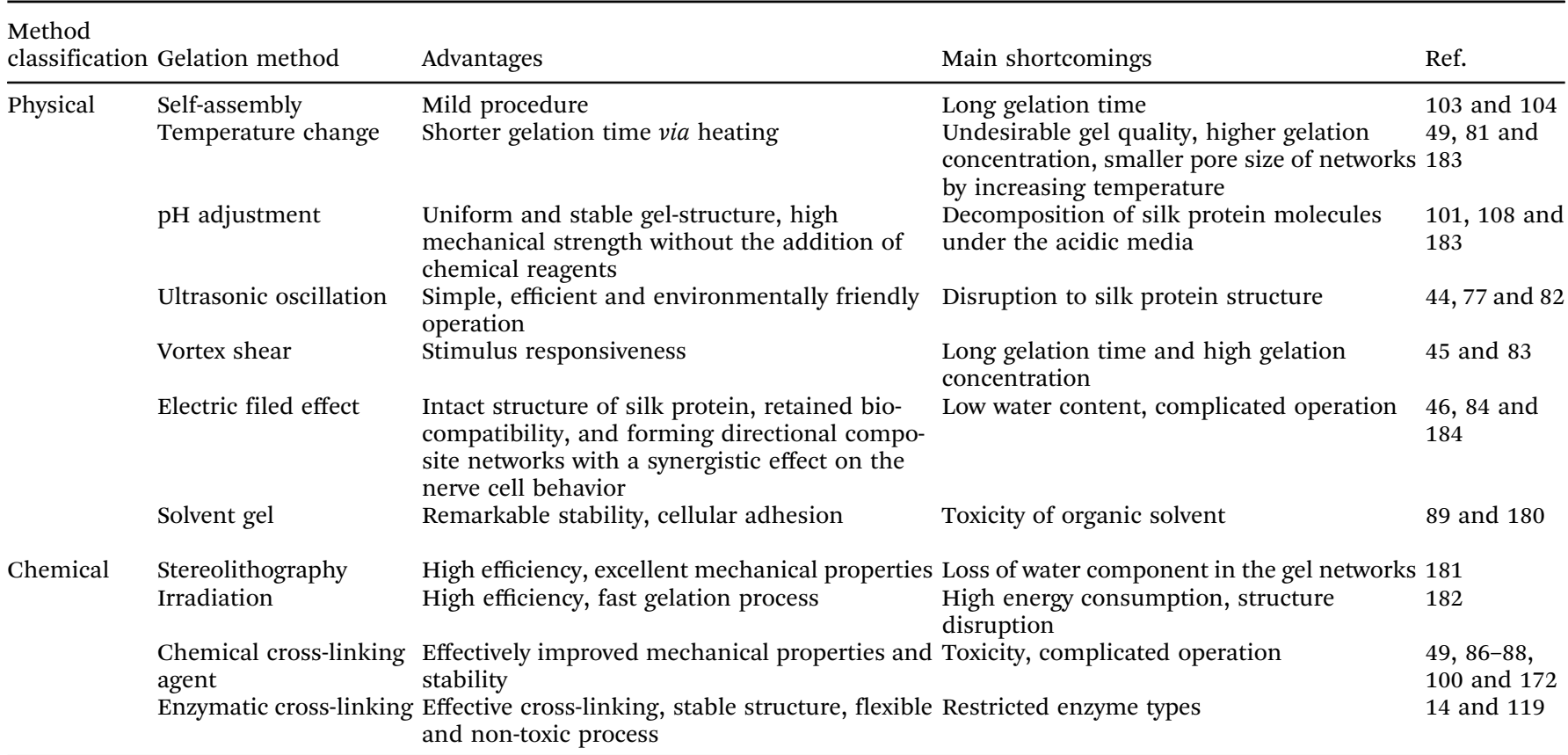

$\beta$-sheet and further aggregate to form a spatial network structure, thereby forming a stable silk protein hydrogel with controllable mechanical properties.

In general, a hydrogel material must be characterized before application to determine its basic characteristics, mainly microstructure and morphology, ${ }^{89}$ porosity, ${ }^{90}$ water content, ${ }^{91}$ swelling properties, ${ }^{92}$ rheological behavior and mechanical properties, ${ }^{93}$ biocompatibility ${ }^{94}$ and biodegradability. ${ }^{95}$ In applications using silk protein hydrogels, whether these basic properties change or the degree of change is an important factor that needs to be considered. The basic properties and kinetic factors affect the temporal and spatial dynamic behavior changes of silk protein hydrogels, thereby controlling the actual utility of hydrogels in specific applications. ${ }^{96}$ Hydrogel materials generally have shape plasticity, which is convenient for later processing to obtain an ideal hydrogel shape. Since the processing conditions will greatly affect the properties of the hydrogel, it is desirable to strictly control and optimize processing to maintain the characteristics of the hydrogel while avoiding mechanical damage. ${ }^{97}$ The development and improvement of the silk protein hydrogel microfluidic system can provide assurance in terms of performance. ${ }^{98}$

When bubbles are removed by ultrasound, the collision between molecules in the solution will be accelerated, causing the local temperature and pressure of the solution to increase. The synergistic effect of hydrogen bonding, hydrophobic forces, and static electricity leads to dehydration of the molecular chains, causing the aggregation of silk fibroin molecules and accelerating the "sol-gel" transformation. ${ }^{99}$ Wang et al. ${ }^{44}$ used the ultrasonic method to treat silk fibroin aqueous solution and optimized the parameters to obtain degradable hydrogels with elastic moduli up to $369-1712 \mathrm{kPa}$, with a treatment time of 0.5-2.0 h. After ultrasound, silk fibroin hydrogels of different concentrations can achieve a three-dimensional uniform loading of human bone marrow mesenchymal stem cells (hBMSCs). After 21 days of incubation, the cells maintained high survival and growth rates. A swirling shear force is applied to the highconcentration silk fibroin solution and the resulting rotational stretching force causes the molecular orientation and chain stretching to change, and the molecular chain spacing and distribution to be affected, with the molecular conformation tending to shift to $\beta$-sheets. Yucel et al. ${ }^{83}$ and Rockwood et $a l^{45}$ used the swirling shear method to explore the gelation conditions of silk fibroin. The former used a speed of $3200 \mathrm{rpm}$ to compare the hydrogel under swirling shear for 2 and 5 minutes. The latter conducted gel condition optimization experiments to determine the correlation between the degree of silk fibroin gelation and the action time of the shearing force. Similarly, electrification can rapidly assemble metastable silk fibroin nanoparticles into larger nanometers or microspheres ranging in size from tens of nanometers to several microns, which promotes protein aggregation and gradually forms silk fibroin hydrogels. ${ }^{46,84}$ By adding the crosslinking agent epoxy compound diglycidyl ether (PGDE), ${ }^{100}$ the silk protein hydrogel can produce a dense and uniform structure with high transparency and strong flexibility, with a compression deformation rate greater than $60 \%$ and a pressure greater than $100 \mathrm{~g} \mathrm{~mm}^{-2}$. Based on the above basic research, we urgently need to develop a specific and controllable rapid prototyping method to improve the structural stability of silk protein hydrogels.

Hydrogels with uniform structure and stability can be formed by simple physical gelling methods such as $\mathrm{pH}$ adjustment, cyclonic shear and ultrasonic oscillation. The preparation process conditions are mild, without the incorporation of any chemical cross-linking agent, and has an environmental response (electrosensitivity, photosensitivity and temperature sensitivity, etc.), which is widely used in injectable hydrogels for 
biomedicine. ${ }^{101}$ However, the hydrogels prepared by physical methods have great brittleness and poor elasticity, and often have unsatisfactory mechanical strength and are easy to collapse and break easily. The chemical cross-linking method can effectively make up for this deficiency. The incorporation of different chemical cross-linking agents can make the formed hydrogel more stable, greatly improve the mechanical properties, and can give the hydrogel special adhesion. The cell growth factor and biological enzymes and other biologically active substances are well fixed on the surface of the silk protein hydrogel. The performance and function of the hydrogel prepared by the chemical cross-linking method are impressive, but the problems of biocompatibility and biodegradability have to be considered. ${ }^{102}$ In order to overcome this difficulty, researchers continue to try to prepare the hydrogel by using the enzymatic cross-linking method. This method not only avoids the possibility of reducing biocompatibility and enhances the controllability of biodegradability, but also has physical and chemical advantages and can be an in situ gel. However, enzymatic methods tend to be more costly, but are safer and more effective. Table 1 lists the advantages and disadvantages of different preparation methods of silk protein hydrogels. In recent years, the research trend is reflected in the preparation of different functional composite hydrogels. No matter what method is used in future research, hydrogels can be endowed with the corresponding required characteristics to meet the realization of different functions.

3.1.2. Formation mechanism and modification research. Regenerated silk fibroin aqueous solution is a protein sol liquid of natural origin in which the protein molecules mainly exist in the form of amphiphilic 'multiblock' molecular chains which can spontaneously aggregate or assemble to form gels when affected by specific physical or chemical factors. ${ }^{103,104}$ The silk fibroin molecule is composed of three subunits: the $\mathrm{L}$ chain, $\mathrm{H}$ chain and glycoprotein P25. It is rich in polar groups such as hydroxyl, amino, carboxyl and amide bonds. The mole fraction of the two hydrophobic residues of glycine and alanine in the repetitive sequence GAGAGS accounts for approximately $79 \%$, making it relatively difficult to chemically cross-link silk fibroin molecules, but very easy to change from random coils to $\beta$-sheets under the action of physical factors. The physical action of the hydrophobic region eventually leads to gelation of the system. ${ }^{2,37,105-107}$ Infrared spectroscopy (FTIR) and circular dichromatography (CD) analysis show that the $\beta$-sheet content in an aqueous solution of regenerated silk fibroin is very low. ${ }^{9}$ In the initial stage of gelation, there are only weak interactions between protein molecular chains and no change in the secondary structure. At this time, the $\beta$-sheet content is relatively stable. This stage is a reversible gelation process. ${ }^{108}$ During the execution stage of the gel process, the secondary structure undergoes irreversible changes, and the $\beta$-sheet content increases significantly, forming a three-dimensional network structure with a large number of cross-linking points, and finally forming a stable hydrogel. ${ }^{67,108}$ Hydrogen bonding and electrostatic effects play a stabilizing role in this network structure. Therefore, the fundamental driving force for the formation of regenerated silk fibroin hydrogels is to promote the conformational transformation, that is, to produce an interpenetrating network structure of $\beta$-sheets from a small amount to a large amount and from disorder to order.

Mechanical analysis shows that regenerated silk fibroin aqueous solution is a dynamically stable but thermodynamically unstable sol system, and the lowest energy effect causes it to finally form a relatively stable three-dimensional network porous hydrogel. However, the types and morphological structure of regenerated silk fibroin hydrogel materials are unitary at present, and their mechanical properties often fail to reach the desired value, not meeting the practical requirements for biomaterials. This inevitably requires a more in-depth exploration of the structure, morphology, performance and function of the hydrogel, with the corresponding modification research gradually maturing, developing and improving. ${ }^{109}$ The surface chemical properties of natural silk fibroin fibers are relatively stable, and their main constituent amino acid sequences do not have strong active residues. The relevant modification studies are mainly devoted to coupling or modifying the amino, carboxyl, hydroxyl and guanidine groups of the side chains in the amorphous zone, ${ }^{110,111}$ such as through phosphorylation, amidation and graft copolymerization methods. Alternatively, silk fibroin can be mixed with other polymer materials in different proportions to improve the mechanical and biological properties of hydrogel materials. ${ }^{112}$ Gotoh et al. ${ }^{113}$ coupled polyethylene glycol (PEG) molecules with a degree of polymerization of approximately 210 to the tyrosine side chain residues of silk fibroin through a melamine chloride coupling reaction, making the modified silk fibroin more easily form a $\beta$-sheet structure and enhancing the hydrophilicity of silk fibroin. Huang et al. ${ }^{114}$ used gelatin and dopamine to prepare a kind of macroporous gel with an interpenetrating network structure through covalent cross-linking, giving it good compressibility and mechanical properties. This gel has good biocompatibility and biodegradability, making it suitable for application in living animals. Its biodegradability eliminates the harm caused by repeated opening of wounds. As an intelligent drug delivery system, an injectable temperature-sensitive hydrogel composed of a sodium alginate/poly- $N$-isopropylacrylamide graft copolymer continuously releases drug-containing micelles, with great potential for overcoming multidrug resistance in tumor cells during cancer treatment. ${ }^{115}$

\subsection{Silk protein composite hydrogel}

Silk protein itself has excellent biocompatibility and biodegradability, but compared with its excellent biological properties, its mechanical properties are often not ideal, with the disadvantages of low mechanical strength, poor gel quality, low molding efficiency, insufficient water retention performance, poor antibacterial properties, and defects in soft tissue repair. To compensate for and reduce such defects, the general approach adopted by scientific researchers has been to dope some functional nanomaterials or functional polymers into silk protein aqueous solutions for modification to obtain functional silk protein composite hydrogel materials (Table 2). Through a combination of quaternization and mechanical homogenization peeling, cationic silk nanofibers 
Table 2 Preparations, performances and functional applications of several silk protein composite hydrogels

\begin{tabular}{|c|c|c|c|}
\hline $\begin{array}{l}\text { Silk protein } \\
\text { composite } \\
\text { hydrogel }\end{array}$ & Method & Purpose & Mechanical properties \\
\hline SF-HA & $\begin{array}{l}\text { Blending and } \\
\text { stirring }\end{array}$ & $\begin{array}{l}\text { Mechanical properties and } \\
\text { organic-inorganic components } \\
\text { similar to natural bones are } \\
\text { achieved while maintaining } \\
\text { injectable properties }\end{array}$ & $\begin{array}{l}\text { The modulus is } \sim 21 \mathrm{kPa} \\
\text { and the stiffness is large }\end{array}$ \\
\hline SF-gelatin & $\begin{array}{l}\text { Ultrasonic treat- } \\
\text { ment \& Genipin- } \\
\text { crosslinked }\end{array}$ & $\begin{array}{l}\text { Explore nature-derived hydro- } \\
\text { gels as active substrates to guide } \\
\text { pluripotent cell proliferation } \\
\text { and differentiation into the } \\
\text { neural lineage }\end{array}$ & High storage modulus \\
\hline SF-PEG2 & $\begin{array}{l}\text { Chemical mod- } \\
\text { ification with } \\
\text { actPEG2 }\end{array}$ & Enhance hydrophilicity & Not involved \\
\hline SF-GO & $\begin{array}{l}\text { Mechanical } \\
\text { vortex }\end{array}$ & Improve mechanical strength & $\begin{array}{l}\text { High tensile strength } \\
(221 \pm 16 \mathrm{MPa}), \text { failure } \\
\text { strain }(1.8 \pm 0.4 \%)\end{array}$ \\
\hline SF-Silk & $\begin{array}{l}\text { Ultrasound } \\
\text { induction }\end{array}$ & $\begin{array}{l}\text { Construct the best mechanical } \\
\text { strength structure }\end{array}$ & $\begin{array}{l}\text { The highest Young's } \\
\text { modulus }(500 \mu \mathrm{m} \text { fibers, } \\
34.0 \pm 3.1 \mathrm{kPa}) \text {, highest } \\
\text { dynamic modulus at } 1 \mathrm{~Hz} \\
(357.2 \pm 45.7 \mathrm{kPa})\end{array}$ \\
\hline SF-LCG & $\begin{array}{l}\text { All-aqueous LCG } \\
\text { processing } \\
\text { method }\end{array}$ & $\begin{array}{l}\text { Obtain a hydrogel with con- } \\
\text { trollable porosity and sufficient } \\
\text { mechanical strength }\end{array}$ & $\begin{array}{l}\text { The compressive mod- } \\
\text { ulus }(0.35-0.091 \mathrm{MPa}) \\
\text { the tensile modulus } \\
(0.27-0.074 \mathrm{MPa})\end{array}$ \\
\hline SF-PU & $\begin{array}{l}\text { In situ } \\
\text { crosslinking }\end{array}$ & $\begin{array}{l}\text { New hydrogel for nuclear } \\
\text { prosthesis }\end{array}$ & $\begin{array}{l}\text { Young's modulus } \\
(0.2-4 \mathrm{MPa}) \text {, high } \\
\text { strength and elasticity }\end{array}$ \\
\hline SA-RSF-C18M & $\begin{array}{l}\text { Hydrophobic } \\
\text { interaction and } \\
\text { ionic } \\
\text { crosslinking }\end{array}$ & $\begin{array}{l}\text { Design a self-healing HA hydro- } \\
\text { gel based on strong hydrophobic } \\
\text { interaction }\end{array}$ & $\begin{array}{l}\text { The mechanical strength } \\
\text { increases with the } \\
\text { increase of C18M } \\
\text { concentration }\end{array}$ \\
\hline PSB & $\begin{array}{l}\text { Mechanical } \\
\text { stirring }\end{array}$ & $\begin{array}{l}\text { Develop novel hydrogel iono- } \\
\text { tronic devices }\end{array}$ & $\begin{array}{l}\text { Maximum strain } \\
(>5000 \%) \text {, elastic } \\
\text { modulus }(100 \mathrm{kPa})\end{array}$ \\
\hline
\end{tabular}

Specific

conditions

Existing shortcomings Ref.

HA: Hydroxyapatite; GO: graphene oxide; LCG: liquid crystalline gelating; PU: polyurethane; SA: sodium alginate; C18M: stearyl methacrylate; PSB: polyvinyl alcohol-RSF-borax.

(SilkNFs) with a thickness of $4 \mathrm{~nm}$ and an aspect ratio of up to 500 were successfully peeled from natural cocoons. ${ }^{116}$ These positively charged cationic SilkNFs can be combined with different types of negatively charged biological nanofibers to obtain membranes or gels with an asymmetric structure. This green cationic biomass fiber stripping method is an effective method for the preparation of biological nanomaterials, and can be applied to the fields of ionic flexible electronic devices, renewable energy and sustainable nanotechnology. Studies have shown that blending with graphene oxide can increase the mechanical strength of silk fibroin hydrogels. For example, graphene oxide can be blended into silk fibroin to prepare a silk fibroin/graphene oxide composite hydrogel system and the results show that controlling the blending ratio of graphene oxide can increase the breaking strength of a composite hydrogel system to 5 times that of a pure silk protein hydrogel. ${ }^{117}$

Among the many silk protein biomaterials that have been developed, silk protein hydrogels have good affinity with cells, do not cause immune rejection when implanted in the body, are biodegradable and easy to absorb, and their internal structure and advantages of a similar extracellular matrix structure have attracted the wide attention of researchers, and have gradually been developed into a new type of cell scaffold material. ${ }^{9}$ The team of Prof. David L. Kaplan from Tufts University in the United States used a vortex oscillator to conduct high-speed swirling shear on the silk protein solution. $^{83}$ The rapid movement and entanglement among the silk protein molecular chain segments accelerated the transition from a random coil state to $\beta$-sheet state and accelerated the gelation process of silk protein. The research group of Prof. Zhengzhong Shao of Fudan University treated the regenerated silk protein solution with an ethanol-water mixed solution to prepare a new type of silk protein-ethanol gel. ${ }^{89}$ The team of Prof. Baoqi Zuo from Soochow University rationally designed an ion conductive hydrogel (named PBST) by mixing polyvinyl alcohol (PVA), borax, silk fibroin and tannic acid (TA) in proportions. The PBST hydrogel has both antibacterial properties and good biocompatibility, which provides a safety guarantee for its use as a flexible wearable strain sensor. ${ }^{118} \mathrm{Lv}$ et al. ${ }^{49}$ heated the collagen to $40{ }^{\circ} \mathrm{C}$ to dissolve it in silk protein solution, and then added different contents of carbodiimide 
(EDC) to it to promote the chemical cross-linking reaction between collagen and silk protein molecules. A hydrogel with a strength of 3-10 $\mathrm{kPa}$ and a high temperature resistance of $80{ }^{\circ} \mathrm{C}$ was prepared. Li et al. ${ }^{119}$ first prepared tyrosine-modified pullulan polysaccharide, and then cross-linked it with silk protein with horseradish peroxidase and $\mathrm{H}_{2} \mathrm{O}_{2}$ to obtain a silk protein-pululan polysaccharide hydrogel. Mandal et al. ${ }^{120}$ mixed silk fibroin and polyacrylamide to prepare a semiinterpenetrating network hydrogel. By changing the proportion of the two components, important parameters such as mechanical strength, water content, swelling rate and porosity could be obtained, so as to control the characteristics of the hydrogel to meet the specific needs of tissue engineering. The results show that the hydrogel has excellent mechanical properties and good biocompatibility. Partlow et al. ${ }^{14}$ successfully prepared a covalent cross-linking hydrogel based on silk fiber with significant elasticity through the use of a biological cross-linking agent (horseradish peroxide, HRP), but it still failed to reach the desired high mechanical properties in terms of its mechanical properties. Therefore, the combination of excellent mechanical properties and biocompatibility required by biomedicine to develop a novel and robust hydrogel material has great potential in tissue engineering and other biomedical fields.

Based on the basic theory of molecular diffusion and the in situ formation of polymer phases, Daelemans et al. ${ }^{121}$ proposed a new method that makes full use of mutual diffusion to adjust the adhesion between electrospun nanofibers and the matrix, and applied this method to thermoplastic nanofibers and a thermosetting matrix. It should be noted that the inherent size of the nanofibers is a limiting factor. When the curing temperature is too high, poly( $\varepsilon$-caprolactone) completely dissolves into epoxy resin, thereby making the nanofiber morphology disappear. A silk protein/hydroxyapatite composite hydrogel system can be prepared by combining hydroxyapatite with silk protein. The blend of hydroxyapatite effectively simulated the composition of bone and was more conducive to the culture of osteocytes. ${ }^{122,123}$ Due to this special multi-level micro/nano composite structure and flexible material composition, electrospinning technology provides an effective way to prepare super-infiltrated surfaces. For example, Hou et al. ${ }^{124}$ prepared multi-level structured micro/nano composite fibers based on electrospinning, which were used in self-cleaning, oilwater separation, emulsion separation, organic liquid separation, directional water collection, liquid unidirectional penetration, and intelligent response. In-depth research has been conducted on material applications in other fields, and progress has been made to a certain extent. In summary, due to certain associated defects in silk protein, the application of pure silk protein hydrogel materials in biomedicine is often limited. Therefore, current and future research seeks to combine silk protein hydrogels with one or even multiple functional materials.

\subsection{Genetically engineered silk-elastin-like protein hydrogels}

The development of biochemistry and molecular biology has provided a reliable foundation for silk protein genetic engineering projects. Among these, gene recombination technology is an effective way to obtain proteins with similar composition, structure and function to natural animal silk fibers. ${ }^{125}$ The demand for new personalized biomaterials continues to increase, and genetic engineering provides a new way to design new biopolymers to match the specific functions of biomaterials. ${ }^{126}$ Using genetic engineering technology to modify silk protein at the molecular level, we can obtain biomaterials with new functions, such as genetically engineered functional silk protein hydrogel, so that the application scenarios are diversified to meet the needs of modern biomedicine.

It has been reported that genes promoting calcium ion binding were introduced into silkworm eggs by microinjection, and silk proteins with strong calcium ion binding ability were obtained through expression, which can be used for the preparation of bone repair materials. ${ }^{127}$ However, robust elastic animal silk fiber hydrogels with biocompatibility have rarely been reported, and these new biomaterials often have important applications in the field of biomedicine, and are in high demand. Therefore, nanotechnology based on a bottomup design method has been widely favored in the application of self-assembled polypeptides in biomimetic structures and biological nanomaterials. ${ }^{79,128,129}$ In addition, we can design biobased materials with desirable properties by utilizing the chemical diversity hidden in various amino acid residues. ${ }^{130}$ Current research prominently uses genetic engineering methods to design and develop a new type of stimulus-responsive hydrogel, that is, genetically engineered silk-elastin-like protein polymer (SELP) hydrogels with coding enzyme cross-linking sites. Hydrogels basically possess all the elasticity of soft tissues, meeting the special requirements of regenerative medicine materials and equipment. ${ }^{131}$ Among these, silk elastin-like protein is mainly composed of silk fiber repetitive blocks (GAGAGS) and mammalian elastin-like blocks (GVGVP), ${ }^{79}$ which provide flexibility to the protein and ensure high cross-linking density inside the hydrogel. The structure of SELPs can be controlled at the level of a single amino acid residue. For this purpose, the addition of different functional amino acid residue sequences can achieve hierarchical self-assembly of the microstructure, triggering stimulus sensitivity and biometric recognition. Affected by temperature regulation, incubation at normal body temperature or slightly higher ambient temperatures can result in the formation of hydrogen bonds between filamentous units and cause crystallization of the silk protein solution, thereby promoting the formation of hydrogels in the SELP solution system, which is advantageous for injectable biomedical applications. ${ }^{132}$

As a starting point for understanding the elastic dynamic protein system, Urry et al. ${ }^{133}$ performed a groundbreaking study, on the aggregation of elastin-like proteins in solution, laying a theoretical foundation for peptide sequence chemistry and stimulus response. SELP-47K, SELP-415K and SELP-815K are typical examples of protein hydrogel formation. The crosslinking density of the hydrogels corresponding to these three types of silk elastin follows the order of SELP-47K $>$ SELP-815K $>$ SELP-415K. ${ }^{134}$ This shows that the length of the silk elastin block is an important factor in controlling the spacing of the hydrogel cross-linking network, and that the stiffness of the 
three-dimensional structure of the hydrogel is regulated by the length of the silk elastin block. Chemotherapeutic drugs of doxorubicin and sorafenib were incorporated into the SELP$815 \mathrm{~K}$ solution of liquid chemical embolization agents for the clinical treatment of metaphase hepatocellular carcinoma. ${ }^{135}$ Among these, the repeat unit body of SELP-815K includes 8 silk (S) units, 15 elastin (E) units and 1 lysine (K)-modified elastin unit. After genetic engineering modification its molecular weight is $\sim 65 \mathrm{kDa}$ and the complete amino acid sequence is: ${ }^{79,134}$

MDPVVLQRRDWENPGVTQLNRLAAHPPFASDPM[GAGS(GAGAGS $)_{2}(\text { GVGVP })_{4}$ GKGVP(GVGVP) ${ }_{11}$ (GAGAGS $) 5$ GAGA $]_{6}$ MDPGRYQDLRSHHHHHH.

Injectable SELP-47K and SELP-815K hydrogels have also been studied and prepared, and they have mainly been used to selectively prevent tumor blood clogging as a new chemotherapy strategy. ${ }^{136}$ Swelling of the SELP-47K hydrogel is not affected by physical factors such as external temperature, $\mathrm{pH}$ value and ionic strength and has good mechanical stability. ${ }^{137}$ In contrast, SELP415K hydrogels exhibit swelling properties that are sensitive to temperature and ionic strength ${ }^{138}$ and in some special cases, it is still desirable to have stimulus-sensitive swelling and release properties. Although research on SELP hydrogels is still in the preliminary stages, it is possible to prepare silk elastin copolyprotein hydrogels with the help of various mechanical properties, noise reduction and biological activity signals. The application prospects of the multi-stimulus response hydrogel design of integrated modeling and genetic engineering silk elastin in the biomedical field cannot be underestimated. ${ }^{139}$

\section{Biomedical applications of silk protein hydrogel}

Natural polymer materials such as gelatin, chitosan, hyaluronic acid and sodium alginate have problems such as an unstable structure, poor plasticity and difficulty in controlling the degradation rate. In addition, their extraction process has high requirements, and the residue of surfactant and the cross-linking curing agent added in the preparation process will produce toxicity and side effects on the body. In contrast, among natural polymers, silk protein has an adjustable molecular structure and mechanical properties, as well as excellent biocompatibility and biodegradability, so it is selected as one of the most ideal raw materials for high-performance hydrogel materials. ${ }^{6,29,64}$ Based on the prominent advantages of silk protein in natural polymers, researchers are increasingly interested in the low-toxic/non-toxic material of silk protein with excellent biocompatibility, which has greatly promoted the development of biomedicine. In this section, the biomedical applications of silk protein hydrogels are classified into four fields, including tissue engineering, controlled drug release, injectable hydrogel construction and intelligent monitoring/sensing, as shown in Fig. 1.

\subsection{Tissue engineering}

Recently, researchers have focused on the development of a suitable tissue engineering scaffold material for bone tissue and cartilage tissue repair. First, silk protein hydrogels can be used as a model for the study of cartilage formation mechanisms. At the same time, they can effectively maintain the phenotype of chondrocytes without triggering the dedifferentiation of chondrocytes to form fibroblasts, so they can be used as a new degradable scaffold cartilage material. ${ }^{12}$ To accurately simulate the structure and composition of the extracellular matrix of natural cartilage, Yodmuang et al. $^{140}$ obtained silk micron fibers by an alkaline hydrolysis method and prepared a fiber-reinforced bionic hydrogel with mechanical properties similar to those of natural cartilage by combining it with a silk fibroin protein hydrogel. The hydrogel has the equilibrium modulus simulated to natural tissue, and provides a good mechanical microenvironment and tissue structure framework for mature chondrocytes, which is convenient for the deposition of the extracellular matrix of chondrocytes and is very suitable for cartilage tissue engineering. Articular cartilage is difficult to recover after trauma. For this reason, Bonaldar et al. ${ }^{141}$ used electrospun fibers to mix chitosan/ glycerophosphate hydrogels to enhance the mechanical properties. At the same time, the results of cell inoculation and culture showed that the glycosaminoglycan (GAG) and collagen content was significantly increased, meeting the requirements for maintaining the formation of a chondrocyte phenotype. This result can be used as proof of artificial cartilage tissue preparation. At the same time, silk protein hydrogel composite materials reinforced by silk microfibers have outstanding performance in promoting the growth of chondrocytes, providing a new idea for preparing silk protein composite hydrogel materials based on excellent interfacial properties. ${ }^{142}$ The scaffold has an extremely important effect on osteochondral regeneration and is the core component of tissue engineering.

Based on 3D printing technology, Zhang et al. ${ }^{78}$ designed and successfully prepared a gradient scaffold with a three-layer structure for the first time, which can accurately imitate the structure of cartilage, calcified cartilage and subchondral bone, promoting the application of hydrogel scaffolds in the field of osteochondral tissue engineering, and having important reference significance for the development of silk protein hydrogels in cartilage tissue engineering. Second, the limitations of autologous or exogenous bone have stimulated the development of many different bone substitutes and have caused many adverse social and economic effects. ${ }^{143}$ In previous work, Diab et al. ${ }^{144}$ established a rat femoral segment defect model to study the BMP-2 delivery system composed of electrospun polycaprolactone nanofiber mesh tubes and silk fibroin hydrogel, which can obviously promote the formation of new bone and significantly improve the biomechanical properties of new bone and provides an effective theoretical foundation for the functional repair of large bone defects. The inherent fragility of some biomaterials has greatly restricted the repair methods of bone regenerative medicine, so the repair of osteoporotic irregular bone defects is still a difficult challenge facing clinical medicine. ${ }^{145,146}$ In response to such problems, $\mathrm{SiO}_{2}-\mathrm{CaO}$ glass nanofibers with good flexibility and biological activity can be prepared by adjusting the molecular conformation and crystalline state of $\mathrm{SiO}_{2}-\mathrm{CaO}$, and flexible $\mathrm{SiO}_{2}-$ $\mathrm{CaO}$ nanofibers can be further combined with chitosan solution. After homogeneous dispersion and freeze-drying, a self-expanding 
$\mathrm{SiO}_{2}-\mathrm{CaO}$ nanofiber/chitosan $\left(\mathrm{SiO}_{2}-\mathrm{CaO} \quad \mathrm{NF} / \mathrm{CS}\right)$ threedimensional scaffold was prepared. ${ }^{145}$ The micro/nano multilevel structure of the $\mathrm{SiO}_{2}-\mathrm{CaO} \mathrm{NF} / \mathrm{CS}$ scaffold closely mimics the extracellular matrix of bone tissue, can promote the proliferation and migration of mesenchymal stem cells, and exhibits good biocompatibility and biological activity in vitro. Therefore, an elastic porous scaffold based on flexible bioactive glass nanofibers, meeting the minimally invasive implantation requirements will become a new type of bone scaffold to replace the bone defects associated with osteoporosis with irregular shapes. Lee et al. ${ }^{143}$ inspired by the nature of plantderived phytochemicals and inorganic-organic analogs of bone extracellular matrix, developed a nanoclay-organic hydrogel bone sealant (NoBS) system, which can be used for the healing of damaged bones. In view of this, Ding et al. ${ }^{13}$ used the thixotropic properties of silk protein hydrogels to construct an injectable nanoscale system and designed and prepared silk protein nanofiber-hydroxyapatite composite hydrogels, which can both repair irregular bone defects and promote bone tissue repair. These hydrogels can be used for in situ bone tissue repair. Finally, summarizing the abovementioned cartilage and bone tissue engineering scaffolds and other high mechanical strength bearing materials used in human tissue engineering research, we know that giving hydrogel materials self-repairing capabilities can greatly improve their service life and functional reliability. ${ }^{147}$

In recent years, scientists have continuously explored the potential uses of silk protein and its composite hydrogel materials in the field of biomedicine and have made achievements in tissue engineering applications such as nerve and blood vessel reconstruction. Trauma, such as brain injury and stroke, is often difficult to cure, causing adult nerve cell regeneration to be weakened or even lost. A silk protein hydrogel modified by covalently bound IKVAV polypeptide can promote the proliferation and differentiation of nerve cells and enhance their cell viability and is an ideal material for the repair of brain nerve tissue. ${ }^{51,148}$ Sun et al. ${ }^{51}$ used a combination of ultrasonic treatment and genipin chemical cross-linking to prepare gelatin-silk fibroin composite hydrogel systems in different proportions. Mouse embryonic stem cells cultured on the composite hydrogel were used for 15 days. After that, they maintain vitality and proliferate, and the composite hydrogel can induce embryonic stem cells to differentiate into epithelial ectoderm. Furthermore, the silk fibroin hydrogel modified by the laminin core sequence IKVAV polypeptide shows higher cell activity and upregulated neuron differentiation ability and has been successfully applied to medical scaffold materials for repairing or rebuilding brain damage. Silk fibroin hydrogels have excellent mechanical strength and blood flow resistance for blood vessel transplantation, and the degradation products will not cause inflammation in the body, showing great potential for vascular tissue engineering applications. Cheng et al. ${ }^{149}$ used short peptide gel agents (such as NapFF) to induce rapid gelation of silk fibroin to obtain structurally stable silk fibroin hydrogels and functionalized silk fibroin hydrogels using a novel peptide gelling agent (NapFFRGD) with an Arg-Gly-Asp (RGD) sequence. Encapsulating vascular endothelial growth factor (VEGF) and subcutaneously injecting it can effectively promote the regeneration of new blood vessels in mice. The potential uses of silk protein hydrogels in other tissue engineering applications are continuously emerging. For example, transparent silk protein hydrogels with excellent optical properties can be prepared, regulating the nanostructure of silk protein hydrogels by adding polar volatile organic solvents such as acetone, which may be applied to artificial corneas. ${ }^{52}$

Nanotechnology allows silk proteins to be transformed into nanoscale silk fibers that mimic the structure of the natural extracellular matrix (ECM) to the greatest extent, facilitating cell adhesion, proliferation and differentiation. ${ }^{150}$ Compared with large-size repair materials, nanomaterials have unique and adjustable physical and chemical properties such as particle size, charge, and hydrophobicity. ${ }^{151}$ In addition, a larger specific surface area gives it unique biological properties. ${ }^{152}$ For example, nanoparticles can increase the probability of interaction with the wound site and enhance the penetration of the wound surface, so as to achieve sustained and controllable sustained-release therapy, and ultimately accelerate wound healing. ${ }^{153}$ Min et al. ${ }^{154}$ prepared silk protein nanofiber nonwovens for cell culture of keratinocytes and fibroblasts from heathy people by using electrostatic spinning technology and using formic acid to dissolve the silk protein, and studied its promoting effect on early wound healing. The results show that the nanofibers can be used as a preferred material for wound dressings and tissue engineering scaffolds in the biomedical field. With the rapid development of tissue engineering and the continuous maturity of nanotechnology, it has become possible to develop tissue engineering materials with good biocompatibility and degradability for skin wound repair.

Natural-source silk protein hydrogel materials have become one of the most important materials for replacing or repairing tissue and organ damage in tissue engineering due to their good mechanical and excellent biological properties. ${ }^{155}$ In addition, silk protein hydrogels have various forms of gelation, and chemical modification is simple and easy to achieve. They can be blended with a variety of other biopolymer materials to prepare composite hydrogel materials, showing excellent synergistic effects. ${ }^{156}$ Tissue engineering (cartilage tissue, artificial hard tissue, nerve tissue, etc.) applications have shown great potential for development. Fig. 4 shows the future prospects of tissue engineering hydrogels. One of the current challenges is how to achieve a high degree of fitting of the tissue structure and functional properties of silk protein and its composite hydrogel, as well as the effective construction of the dynamic chemical mechanical environment in vivo.

\subsection{Controlled release of drugs}

With the advancement of social science and technology and the improvement of living standards, the average human life expectancy has been extended, but it inevitably requires avoidance of the frequent medical problems caused by chronic diseases of aging. Many patients with chronic diseases who take medicines throughout their lives assume heavy mental and economic burdens for themselves and their families. In addition, there are always adverse phenomena in the process of taking drugs such as 


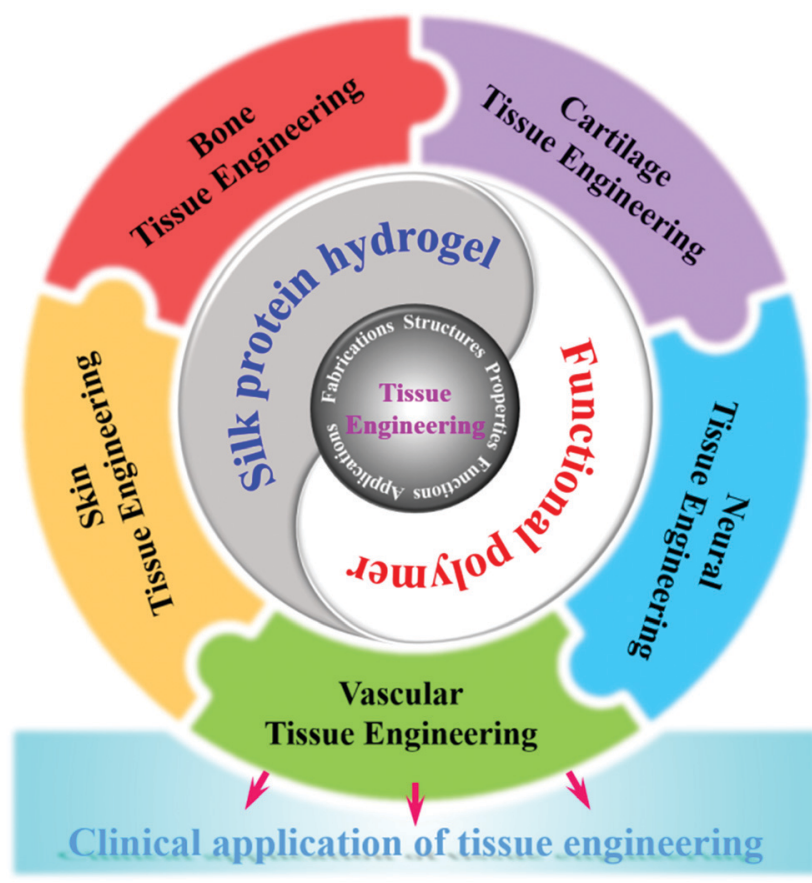

Fig. 4 Prospects for tissue engineering

poor stability, low efficacy, high toxicity and side effects. To solve the problems of frequent drug delivery, low utilization of drug active ingredients, high toxicity and side effects in the treatment of chronic diseases of middle-aged and elderly people it is particularly important to develop a controlled release system for drugs with stable drug performance, good curative effect and high biological safety. ${ }^{157,158}$ The release of drugs in silk protein hydrogels is closely related to the secondary structure of silk protein. The controlled release of drugs can be achieved by changing the content of $\beta$-sheets. The controlled drug release system can effectively slow down the release, absorption, metabolism and excretion of drugs in the body, reduce toxic side effects, and maximize drug efficacy, ${ }^{159}$ the focus of current research in the medical field. Controlled drug release systems are composed of a large number of preparation materials which can be divided into natural preparation materials ${ }^{160}$ (mainly polysaccharides and their derivatives and proteins) and synthetic preparation materials ${ }^{161}$ (polyester, polylactoacetic acid copolymer, etc.) according to their sources. The silk protein hydrogel described in this section is a protein preparation material with the properties of non-toxicity, non-irritation and drug function retention. By changing its composition, crystal type, hydrophobic region content and cross-linking density, the drug loading and drug release amount of the carrier can be controlled. It is expected that it can be used as a drug carrier material to carry proteins such as polypeptides, enzyme antibodies, and large and small molecule drugs in the treatment of diseases. Aqueous solutions of silk protein can be affected by factors such as $\mathrm{pH}$, temperature, ionic strength and cross-linking agent to form hydrogels with different properties. ${ }^{137}$ Changing these influencing factors can control the release properties of hydrogels. However, the release of drugs from hydrogels is restricted by many factors such as the inherent properties of drugs, cross-linking density, pore size and swelling degree. ${ }^{90-93,162}$ Injectable silk fibroin hydrogels have been prepared by blending silk fibroin protein with low molecular weight polyethylene glycol (PEG300 or PEG400). The gelation time ( $<30 \mathrm{~min})$ depends on the PEG concentration (40-45\%) and molecular weight. Subsequently, synthetic insulin was added to the silk fibroin-polyethylene glycol hydrogel and the silk fibroin hydrogel was induced by ultrasound. A comparative study found that the former (containing a higher $\beta$-sheet content) is more effective than the latter. The sustained release effect of insulin is more marked, and the silk fibroin-polyethylene glycol injected subcutaneously into rats shows minimal inflammation and slow degradation, indicating that the hydrogel may meet the needs of drug delivery and tissue regeneration. ${ }^{163}$ Park et al. ${ }^{164}$ controlled the gelation time of silk fibroin aqueous solution by adding methyl cellulose (MC) during the experiment and investigated the relationship between the drug release performance of the hydrogel and the amount of MC added. The results of the study showed that the gelation time was prolonged with increasing the MC content, and the release rate of 5-aminosalicylic acid decreased. The method of adding MC to control the sol-gel transition of SF hydrogels can serve as a new model for the design and customization of novel biomedical materials. The use of thixotropic silk fibroin/hydroxypropyl cellulose hydrogels as a carrier successfully overcomes the shortcomings of low water solubility and poor drug loading effect of curcumin, providing new opportunities for topical anticancer drug delivery. ${ }^{165}$ Seib et al..$^{77}$ successfully prepared a biodegradable injectable drug-loaded silk fibroin hydrogel by means of ultrasonic oscillation, with no obvious swelling phenomenon in PBS buffer, in a water environment, by adjusting the proportion of adriamycin and silk protein to achieve a sustained release effect in the short term, effectively inhibiting the proliferation of tumor cells and the metastasis and spread of cancer cells, laying a theoretical foundation for the research and development of cancer treatment drugs and it is expected to become an advanced drug carrier material for a new generation of cancer treatments. Although the control of drug release using silk protein hydrogels can be achieved at present, the release rate is difficult to accurately control, the start is late, and there are many shortcomings. Relevant research is only carried out on the basis of laboratory feasibility analysis. The major future challenge is realizing the industrialization of drug-loaded silk protein hydrogel materials. There is still a gap preventing real clinical treatment applications.

\subsection{Injectable hydrogels}

In recent years, injectable biomaterials have become one of the most discussed keywords in the field of biomedicine, and hydrogels are one of the most promising injectable biomaterials. Combining the advantages of silk protein degradability in vivo and excellent biocompatibility, ${ }^{166}$ hydrogel injectable biomaterials can minimize pain and adverse reactions in the process of medical implantation, ${ }^{167}$ tissue regeneration ${ }^{168}$ and wound repair ${ }^{169}$ by using the thixotropy of the hydrogel itself. The injectable silk protein hydrogel transforms from a flowing liquid to a gel before and after injection and forms a solid substance at the injection site, such as muscle or epithelial tissue, due to the change in 
molecular conformation in a physiological environment. In view of the excellent 3B properties of the injectable hydrogel and its similar and stable structure and organization, this provides a microenvironment for cell adhesion and growth that can be used as a clinically effective drug carrier and as a common method for inducing the regeneration of defective tissues. Hu et al. ${ }^{170}$ proposed a method to prepare injectable silk fibroin/polyurethane (SF/PU) composite hydrogels through chemical cross-linking under physiological conditions. The SF/PU composite hydrogel was injected through a small incision for one week. Posterior bone marrow stromal cells proliferated significantly and showed good cell viability. In addition, the SF/PU composite injectable hydrogel can completely fill the degenerative area, reduce the risk of implant migration and subsequent disc height loss, and minimize surgical defects; thus, injection hydrogel therapy is a new minimally invasive therapy for the effective treatment of degenerative disc disease. Liu et al. ${ }^{166}$ simulated the formation mechanisms and processing of natural silk and successfully prepared an injectable type with good porosity (pore size 62$580 \mu \mathrm{m}$ ), and high mechanical strength and elasticity (elastic modulus 0.074-0.69 MPa). Silk protein bio-scaffold gel materials have made significant progress in improving the mechanical properties, porous properties, bio-controllable degradation and tissue regeneration performance of injectable hydrogels. The material is expected to have broad application prospects in the areas of local controlled drug release, tissue defect filling, and tissue-induced regeneration. A new type of injectable hydrogel has been generated from the supramolecular assembly of synthetic glycopeptides and is used to simulate the highly glycosylated microenvironment of the extracellular matrix (ECM), promote the adhesion and proliferation of endothelial cells, and further incorporate deferoxammonium (DFO) injected into the subcutaneous tissue of experimental mice to trigger the production of new blood capillaries in the body. ${ }^{171}$ Among these, the glycopeptide hydrogel encapsulating DFO plays an important role as an effective matrix. The construction of the functional vascular network of regenerated tissue requires matrix materials with excellent biocompatibility and cell affinity. Silk protein hydrogels are natural biobased alternative matrix materials that are worthy of choice. Fig. 5 shows a schematic diagram of the injectable hydrogel simulation and its preparation requirements. Developing injectable silk protein hydrogels and broadening their application in the field of biomedical materials is of great significance.

How to ensure the biological safety of injectable silk protein hydrogels and their composite hydrogel materials, how to improve the cell loading efficiency of injectable hydrogels, and how to ensure excellent injection performance for hydrogels are important challenges in the development of regenerative medicine. To solve the above problems, Meng et al. ${ }^{172}$ proposed a surfactant-free hydrophobic association (HA) hydrogel design strategy by dissolving the hydrophobic monomer octadecyl methacrylate (C18M) in amphiphilic silk fibroin (RSF) solution to form a hydrophobic association, and introduced the material as a sacrificial bond into the sodium alginate ion cross-linking network to prepare a multifunctional silk protein-based natural polymer hydrogel with high compressive strength, self-healing,

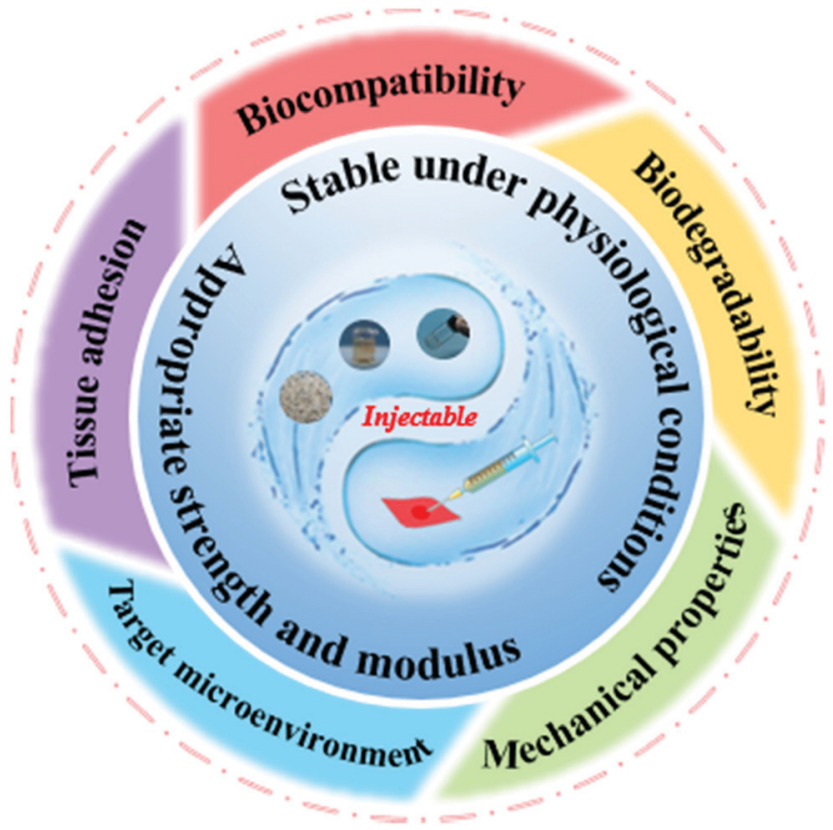

Fig. 5 Properties of desirable injectable hydrogels for biomedical utility.

injectability and biocompatibility. Mixing an injectable silk protein hydrogel with $\mathrm{DFO}^{171}$ to form a continuous drug delivery system for optimizing vascularization is a feasible research strategy. This strategy greatly increases cell load efficiency, induces a wound healing effect, is faster, and can be used to support a variety of organizations forming new blood vessels in the functional repair of their environment. ${ }^{173}$ The formation of new blood vessels in damaged tissues can be controlled by strategic research to provide an effective solution. In the future, it will be necessary to combine and improve the knowledge of existing injectable hydrogels and their development (such as the silk protein/LAPONITE ${ }^{\circledR}$ nanoplatelet hybrid injectable hydrogel materials used in the repair of irregular bone defects ${ }^{174}$ ), and to dedicate attention to natural high polymer material modification and more functional synthetic polymer material research and development, as well as more in-depth research on the mechanism of the interaction between silk protein and the organism environment, in order to further satisfy the application requirements of injectable silk protein hydrogels in the field of regenerative medicine, contributing to the clinical application and transformation of injectable hydrogels.

\subsection{Intelligent monitoring and sensing}

With continuous development and progress in understanding biology-based materials and related manufacturing technologies, flexible wearable electronic sensing products based on silk protein-based advanced materials have received widespread attention, providing new opportunities for human disease diagnosis and treatment, health monitoring, medical care and intelligent nanomachines. Yang et al. ${ }^{175}$ successfully prepared a biocompatible hydrogel strain sensor using polyvinyl alcohol (PVA)/regenerated silk fibroin/borax (PVA/RSF/borax, PSB). In the PSB hydrogel, PVA and borax provide high stretchability and 
conductivity, respectively, while RSF can improve the stability of the hydrogel and increase the water intake through the gel, which has good water retention. The PSB hydrogel demonstrated ultrahigh stretchability (withstanding a strain limit of 5000\%), good water retention, self-healing properties, and adjustable conductivity and adhesion. At the same time, it can be used as a sensing platform for human motion monitoring and medical and health management, as well as interactions between soft robots and the human-machine interface. Seo et al. ${ }^{176}$ developed a biocompatible and strong adhesive based on transparent calcium (CA)-modified silk fibroin which can be used as an epidermal electronic device (including multiple functional properties: repeatability, stretchability and electrical conductivity), and reported the physical mechanism between its interface and adhesion properties, which make it suitable for actual skin applications. At the same time, four custom-designed epidermal systems, capacitive touch sensors, resistive strain sensors, hydrogel-based drug delivery systems, and electrocardiogram monitoring sensors can be firmly adhered to the surface of biological skin through silk fibroin adhesives. Compared with some modified polydimethylsiloxane (PDMS) elastomers ${ }^{177}$ and polyvinyl alcohol-based hydrogel ${ }^{178}$ materials, this adhesive is expected to be a popular candidate material for the next representative skin biomedical sensor. Jo et al. ${ }^{179}$ used silk protein and gold nanowires (AgNWs) to successfully prepare stretchable, shape-stable and well-permeable flexible electronic devices. At the same time, the incorporation of glycerol and $\mathrm{Ca}^{2+}$ can produce polycrystalline crystal protein membranes with the required physical properties. The protein film provides it with high stretchability (up to $400 \%$ ) and skin adhesion in the living environment and can be effectively applied to artificial electronic skin (like real skin). Electronic skin devices can accomplish continuous monitoring of important signals such as strain, electrochemistry, and electrophysiology in daily life conditions and have achieved pioneering achievements in practical applications such as monitoring human health and environmental conditions, as well as preventing and treating diseases. With the rapid development of epidermal and implantable flexible electronic products, enhancing the strong interface between the sensor and the biological surface is both a major challenge and an opportunity to be grasped. Silk proteinbased flexible wearable biosensors have only appeared in recent years. For this reason, we can expect the emergence of new intelligent sensors with higher sensitivity, durability and portability.

\section{Challenges and future prospects}

With the continuous research on silk protein, related problems are gradually solved, and the research process of new products based on the biological activity and functional materials of silk protein will be greatly accelerated. Through the joint efforts of researchers, the mechanical properties of silk protein-based hydrogel materials have been significantly improved, ${ }^{59}$ but the poor mechanical properties of renewable hydrogels based on natural polymers are still the bottleneck that limits their applications in biomedicine. Natural silk protein itself has inherent defects. If there is no functional composite factor (functional nanomaterials or functional polymer materials), pure silk protein hydrogels will be restricted in their practical application. ${ }^{74-79}$ Physical and chemical or biological methods can further improve their performance and improved application in the field of biomedicine. ${ }^{60-62,110-112}$ The chemical cross-linking method is the simplest conventional method for preparing hydrogel materials, which can effectively improve the mechanical properties of hydrogel materials. However, considering the safety of chemical cross-linking agents in the preparation process, the application of chemical cross-linking methods is limited to some extent. ${ }^{102}$ Therefore, seeking an efficient, environmentally friendly, and safe cross-linking method is very important for the preparation of biocompatible hydrogel medical products with high mechanical properties. At the same time, silk proteinbased biomaterials are currently stagnating at the level of cells and small model animals in terms of tissue engineering, drug delivery, intelligent diagnosis and treatment, and genetic engineering. It is impossible to ensure a safe and effective transition to a large animal evaluation system and medical clinical applications. Much research work is still needed in this area. In addition, the large-scale commercial production of recombinant silk protein and genetically modified silk protein is still a difficult challenge. With the rapid development of genetic engineering techniques, we need to meet the challenge and conduct more experiments and explorations to fully discover the potential value of silk protein, a natural biopolymer material with unique properties, so that it can shine in biomedical applications. ${ }^{126}$

The construction of a new type of biomedical material with a controllable structure and plastic performance based on silk protein is an important subject. Research on this will explore and develop whole bio-based silk fiber biomaterials. Through rational design of the polymer chain and hydrogel structure, a hydrogel with high strength in an in vitro environment, nonswelling in a physiological environment, and mechanical stability during degradation can be obtained. Systematic optimization and characterization of its material preparation process and physical and chemical properties, research and evaluation of its potential applications and value in the field of biomedicine, provide a new idea for the construction of highstrength medical hydrogels closer to practical applications.

For this reason, in future research of silk protein hydrogels for applications in biomedicine, it is recommended that the research is conducted with the view of the following five aspects: (1) improve comprehensive mechanical properties to meet its application requirements in tissue engineering; (2) ensure the biosafety of injectable hydrogels and improve their cell loading efficiency; (3) composite modification research based on advanced new functional materials and silk protein hydrogels to obtain more excellent properties; (4) combining new molding methods, such as rapid 3D printing technology, genetic engineering and nanotechnology, to prepare new silk protein hydrogel materials to meet the personalized needs of biomedical applications; and (5) clinical applications require more experimental exploration and attempts.

In the long evolution of human society, the development of biomaterials requires scientific and technological means to 
effectively solve many problems in its development leading to a deeper understanding of the nature of biomaterials and the laws governing their development. From the perspective of the dialectics of nature, the methodology of science and technology plays an important role in guiding the development of biomaterials. Scientific and technological research have played a key role in the development of biomaterials. Finally, we emphasize here that nanoscience and technology have penetrated the field of biomaterials and people have gradually realized the huge development potential of biomaterials, ${ }^{93}$ providing unlimited opportunities for relevant scientific researchers. With the continuous in-depth development of science and technology, the design and preparation of biological functional materials has become one of the most prominent and active directions in the field of life science and medical research and has attracted increasing interest and attention from interdisciplinary researchers and clinicians. This future development trend should not be underestimated.

\section{Conflicts of interest}

The authors declare no conflict of interest.

\section{Acknowledgements}

This work was supported by the Natural Science Foundation of Jiangsu Province (BK20210944), and the Postgraduate Research \& Practice Innovation Program of Jiangsu Province (KYCX20_2964).

\section{References}

1 W. H. Elliott, W. Bonani, D. Maniglio, A. Motta, W. Tan and C. Migliaresi, ACS Appl. Mater. Interfaces, 2015, 7, 12099-12108.

2 D. Jao, X. Y. Mou and X. Hu, J. Funct. Biomater., 2016, 7, 22.

3 Y. Tian, X. J. Jiang, X. Chen, Z. Z. Shao and W. L. Yang, Adv. Mater., 2014, 26, 7393-7398.

4 S. D. Wang, Y. Z. Zhang, G. B. Yin, H. W. Wang and Z. H. Dong, Mater. Sci. Eng., C, 2010, 30, 670-676.

5 K. Y. Luo, Y. H. Yang and Z. Z. Shao, Adv. Funct. Mater., 2016, 26, 872-880.

6 L. T. A. Hong, Y. M. Kim, H. H. Park, D. H. Hwang, Y. X. Cui, E. M. Lee, S. Yahn, J. K. Lee, S. C. Song and B. G. Kim, Nat. Commun., 2017, 8, 533.

7 X. W. Wang, Y. Cu, Z. P. Xiong, Z. Cui and T. Zhang, Adv. Mater., 2014, 26, 1336-1342.

8 P. Tseng, B. Napier, S. W. Zhao, A. N. Mitropoulos, M. B. Applegate, B. Marelli, D. L. Kaplan and F. G. Omenetto, Nat. Nanotech., 2017, 12, 474-480.

9 S. Kapoor and S. C. Kundu, Acta Biomater., 2016, 31, 17-32. 10 Y. S. Yun, S. Y. Cho, J. Shim, B. H. Kim, S. J. Chang, S. J. Baek, Y. S. Huh, Y. Tak, Y. W. Park, S. Park and H. J. Jin, Adv. Mater., 2013, 25, 1993-1998.

11 G. B. Yin, Y. Z. Zhang, S. D. Wang, D. B. Shi, Z. H. Dong and W. G. Fu, J. Biomed. Mater. Res., 2010, 93A, 158-163.

12 Y. P. Singh, N. Bhardwaj and B. B. Mandal, ACS Appl. Mater. Interfaces, 2016, 8, 21236-21249.
13 Z. Z. Ding, H. Y. Han, Z. H. Fan, H. J. Lu, Y. H. Sang, Y. L. Yao, Q. Q. Cheng, Q. Lu and D. L. Kaplan, ACS Appl. Mater. Interfaces, 2017, 9, 16913-16921.

14 B. P. Partlow, C. W. Hanna, J. Rnjak-Kovacina, J. E. Moreau, M. B. Applegate, K. A. Burke, B. Marelli, A. N. Mitropoulos, F. G. Omenetto and D. L. Kaplan, $A d v$. Funct. Mater., 2014, 24, 4615-4624.

15 X. Zhao, H. Wu, B. L. Guo, R. N. Dong, Y. S. Qiu and P. X. Ma, Biomaterials, 2017, 122, 34-47.

16 J. L. Drury and D. J. Mooney, Biomaterials, 2003, 24, 4337-4351.

17 S. Ghosh, S. T. Parker, X. Wang, D. L. Kaplan and J. A. Lewis, Adv. Funct. Mater., 2010, 18, 1883-1889.

18 Z. P. Xu, L. Y. Shi, M. Y. Yang, H. P. Zhang and L. J. Zhu, J. Mater. Chem. B, 2015, 3, 3634-3642.

19 H. F. Liu, X. M. Li, G. Zhou, H. B. Fan and Y. B. Fan, Biomaterials, 2011, 32, 3784-3793.

20 S. S. Silva, A. Motta, M. T. Rodrigues, A. F. M. Pinheiro, M. E. Gomes, J. F. Mano, R. L. Reis and C. Migliaresi, Biomacromolecules, 2008, 9, 2764-2774.

21 C. Y. Wang, X. Li, E. L. Gao, M. Q. Jian, K. L. Xia, Q. Wang, Z. P. Xu, T. L. Ren and Y. Y. Zhang, Adv. Mater., 2016, 28, 6640-6648.

22 P. Gentile, V. Chiono, I. Carmagnola and P. V. Hatton, Int. J. Mol. Sci., 2014, 15, 3640-3659.

23 S. Yodmuang, S. L. Mcnamara, A. B. Nover, B. B. Mandal, M. Agarwal, T. N. Kelly, P. G. Chao, C. K. Hung, D. L. Kaplan and G. Vunjaknovakovic, Acta Biomater., 2015, 11, 27-36.

24 B. B. Mandal, S. Kapoor and S. C. Kundu, Biomaterials, 2009, 30, 2826-2836.

25 F. P. Seib, E. M. Pritchard and D. L. Kaplan, Adv. Funct. Mater., 2013, 23, 58-65.

26 O. V. Khutoryanskaya, M. Potgieter and V. V. Khutoryanskiy, Soft Matter, 2010, 6, 551-557.

27 E. S. Gil, S. H. Park, L. W. Tien, B. Trimmer, S. M. Hudson and D. L. Kaplan, Langmuir, 2010, 26, 15614-15624.

28 R. Elia, D. R. Newhide, P. D. Pedevillano, G. R. Reiss, M. A. Firpo, E. W. Hsu, D. L. Kaplan, G. D. Prestwich and R. A. Peattie, J. Biomater. Appl., 2011, 27, 749-762.

29 O. S. Fenton, K. N. Olafson, P. S. Pillai, M. J. Mitchell and R. Langer, Adv. Mater., 2018, 30, 1705328.

30 P. S. Kowalski, C. Bhattacharya, S. Afewerki and R. Langer, ACS Biomater. Sci. Eng., 2018, 4, 3809-3817.

31 A. Datta, A. K. Ghosh and S. C. Kundu, Insect Biochem. Mol. Biol., 2001, 31, 1013-1018.

32 R. Valluzzi, S. Winkler, D. Wilson and D. L. Kaplan, Philos. Trans. R. Soc., B, 2002, 28, 165-167.

33 C. L. Craig and C. Riekel, Comp. Biochem. Physiol., Part B: Biochem. Mol. Biol., 2002, 133, 493-507.

34 C. J. Fu, Z. Z. Shao and V. Fritz, Chem. Commun., 2009, 6515-6529.

35 F. G. Omenetto and D. L. Kaplan, Science, 2010, 329, 528-531.

36 M. Z. Li, W. Tao, S. Z. Lu and C. X. Zhao, Polym. Adv. Technol., 2008, 19, 207-212. 
37 G. H. Altman, F. Diaz, C. Jakuba, T. Calabro, R. L. Horan, J. S. Chen, H. Lu, J. Richmond and D. L. Kaplan, Biomaterials, 2003, 24, 401-416.

38 S. Inoue, K. Tanaka, F. Arisaka, S. Kimura, K. Ohtomo and S. Mizuno, J. Biol. Chem., 2000, 275, 40517-40528.

39 Z. P. Yin, F. Wu, Z. Z. Zheng, D. L. Kaplan, S. C. Kundu and S. Z. Lu, ACS Biomater. Sci. Eng., 2017, 3, 2617-2627.

40 T. D. Sutherland, J. H. Young, S. Weisman, C. Y. Hayashi and D. J. Merritt, Annu. Rev. Entomol., 2010, 55, 171-188.

41 D. L. Kaplan, Introduction to Biopolymers from Renewable Resources, Springer, Berlin, Heidelberg, 1998, pp. 1-29.

42 C. Vepari and D. L. Kaplan, Prog. Polym. Sci., 2007, 32, 991-1007.

43 P. W. Ho and K. M. Hee, Int. J. Nanomed., 2016, 11, 2967-2978.

44 X. Q. Wang, J. A. Kluge, G. G. Leisk and D. L. Kaplan, Biomaterials, 2008, 29, 1054-1064.

45 D. N. Rockwood, R. C. Preda, T. Yücel, X. Q. Wang, M. L. Lovett and D. L. Kaplan, Nat. Protoc., 2011, 6, 1612-1631.

46 G. G. Leisk, T. J. Lo, T. Yucel, Q. Lu and D. L. Kaplan, Adv. Mater., 2010, 22, 711-715.

47 R. R. Mallepally, M. A. Marin and M. A. McHugh, Acta Biomater., 2014, 10, 4419-4424.

48 S. J. Xu, L. Yong and P. Y. Wu, ACS Appl. Mater. Interfaces, 2013, 5, 654-662.

49 Q. Lv, K. Hu, Q. L. Feng and F. Z. Cui, J. Biomed. Mater. Res., Part A, 2008, 84, 198-207.

50 B. B. Mandal, S. Kapoor and S. C. Kundu, Biomaterials, 2009, 30, 2826-2836.

51 W. Sun, T. Incitti, C. Migliares, A. Quattrone, S. Casarosa and A. Motta, J. Tissue Eng. Regener. Med., 2014, 10, 876-887.

52 A. N. Mitropoulos, B. Marelli, C. E. Ghezzi, M. B. Applegate, B. P. Partlow, D. L. Kaplan and F. G. Omenetto, ACS Biomater. Sci. Eng., 2015, 1, 964-970.

53 J. M. Gosline, P. A. Guerette, C. S. Ortlepp and K. N. Savage, J. Exp. Biol., 1999, 202, 3295-3303.

54 Y. F. Ma, Q. L. Feng and X. Bourrat, Mater. Sci. Eng., C, 2013, 33, 2413-2420.

55 M. B. Applegate, B. P. Partlow, J. Coburn, B. Marelli, C. Pirie, R. Pineda, D. L. Kaplan and F. G. Omenetto, Adv. Mater., 2016, 28, 2417-2420.

56 M. Z. Li, Z. Y. Wu, C. S. Zhang, S. Z. Lu, H. J. Yan, D. Huang and H. L. Ye, J. Appl. Polym. Sci., 2001, 79, 2192-2199.

57 I. C. Um, H. Y. Kweon, Y. H. Park and S. Int, J. Biol. Macromol., 2001, 29, 91-97.

58 W. W. Zhang, C. Ye, K. Zheng, J. J. Zhong, Y. Z. Tang, Y. M. Fan, M. J. Buehler, S. J. Ling and D. L. Kaplan, ACS Nano, 2018, 12, 6968-6977.

59 S. Keten, Z. P. Xu, B. Ihle and M. J. Buehler, Nat. Mater., 2010, 9, 359-367.

60 J. Thiele, Y. J. Ma, S. M. C. Bruekers, S. H. Ma and W. T. S. Huck, Adv. Mater., 2014, 26, 125-148.

61 W. Zhang, R. X. Wang, Z. M. Sun, X. W. Zhu, Q. Zhao, T. F. Zhang, A. Cholewinski, F. Yang, B. X. Zhao, R. Pinnaratip, P. K. Forooshanie and B. P. Lee, Chem. Soc. Rev., 2020, 49, 433-464.
62 Q. Feng, J. K. Xu, K. Y. Zhang, H. Yao, N. Y. Zheng, L. Z. Zheng, J. L. Wang, K. C. Wei, X. F. Xiao, L. Qin and L. M. Bian, ACS Central Sci., 2019, 5, 440-450.

63 Y. J. Zhao, Z. Y. Xie, H. C. Gu, C. Zhu and Z. Z. Gu, Chem. Soc. Rev., 2012, 41, 3297-3317.

64 K. Numata, T. Katashima and T. Sakai, Biomacromolecules, 2011, 12, 2137-2144.

65 S. G. Eun, J. F. David, J. S. Richard and M. H. Samuel, Biomacromolecules, 2005, 6, 3079-3087.

66 K. Numata, P. Cebe and D. L. Kaplan, Biomaterials, 2010, 31, 2926-2933.

67 M. Akira, J. Phys. Chem. B, 2006, 110, 21630-21638.

68 H. P. Tan and K. G. Marra, Materials, 2010, 3, 1746-1767.

69 C. Y. Wang, K. L. Xia, H. M. Wang, X. P. Liang, Z. Yin and Y. Y. Zhang, Adv. Mater., 2019, 31, 1801072.

70 Z. Y. Chen, Y. Wang and Y. J. Zhao, Proc. Natl. Acad. Sci. U. S. A., 2020, 117, 18310-18316.

71 X. Q. Dou and C. L. Feng, Adv. Mater., 2017, 29, 1604062.

72 J. J. Ye, T. S. Chu, J. L. Chu, B. B. Gao and B. F. He, ACS Sustainable Chem. Eng., 2019, 7, 18048-18054.

73 W. T. Song, M. Das, Y. D. Xu, X. H. Si, Y. Zhang, Z. H. Tang and X. S. Chen, Mater. Today Nano, 2019, 5, 100029.

74 G. D. Kang, K. H. Lee, C. S. Ki, J. H. Nahm and Y. H. Park, Macromol. Res., 2004, 12, 534-539.

75 K. Numata, S. Yamazaki, T. Katashima, J. A. Chuah, N. Naga and T. Sakai, Macromol. Biosci., 2014, 14, 799-806.

76 J. Zhang, A. M. Zhou, A. P. Deng, Y. Yang, L. H. Gao, Z. C. Zhong and S. L. Yang, Mater. Sci. Eng., C, 2015, 49, 174-182.

77 F. P. Seib, E. M. Pritchard and D. L. Kaplan, Adv. Funct. Mater., 2013, 23, 58-65.

78 H. Zhang, H. F. Huang, G. R. Hao, Y. S. Zhang, H. Ding, Z. J. Fan and L. Y. Sun, Adv. Funct. Mater., 2021, 31, 2006697.

79 J. Chang, X. F. Peng, K. Hijji, J. Cappello, H. Ghandehari, S. D. Solares and J. Seog, J. Am. Chem. Soc., 2011, 133, 1745-1747.

80 C. Ye, J. Ren, Y. L. Wang, W. W. Zhang, C. Qian, J. Han, C. X. Zhang, K. Jin, M. J. Buehler, D. L. Kaplan and S. J. Ling, Matter, 2019, 1, 1411-1425.

81 A. Matsumoto, J. S. Chen, A. L. Collette, U. J. Kim, G. H. Altman, P. Cebe and D. L. Kaplan, J. Phys. Chem. B, 2006, 110, 21630-21638.

82 S. H. Park, H. Cho, E. S. Gil, B. B. Mandal, B. H. Min and D. L. Kaplan, Tissue Eng., Part A, 2011, 17, 2999-3009.

83 T. Yucel, P. Cebe and D. L. Kaplan, Biophys. J., 2009, 97, 2044-2050.

84 Q. Lu, Y. L. Huang, M. Z. Li, B. Q. Zuo, S. Z. Lu, J. N. Wang, H. S. Zhu and D. L. Kaplan, Acta Biomater., 2011, 7, 2394-2400.

85 M. Fini, A. Motta, P. Torricelli, G. Giavaresi, N. N. Aldini, M. Tschon, R. Giardino and C. Migliaresi, Biomaterials, 2005, 26, 3527-3536.

86 X. Chen, W. J. Li, W. Zhong, Y. H. Lu and T. Y. Yu, J. Appl. Polym. Sci., 2015, 65, 2257-2262.

87 H. H. Zhou, Z. G. Wang, H. Q. Cao, H. Y. Hu, Z. K. Luo, X. L. Yang, M. M. Cui and L. Zhou, J. Biomat. Sci-Polym. E., 2019, 30, 1604-1619. 
88 S. S. Silva, A. Motta, M. T. Rodrigues, A. F. M. Pinheiro and C. Migliaresi, Biomacromolecules, 2008, 9, 2764-2774.

89 Z. G. Gong, Y. H. Yang, L. Huang, X. Chen and Z. Z. Shao, Soft Matter, 2010, 6, 1217-1223.

90 Y. Chen, P. G. Miller, X. Ding, C. E. T. Stowell, K. M. Kelly and Y. Wang, Adv. Mater., 2020, 32, 2003761.

91 Y. S. Zhao, B. Z. Zhang, B. W. Yao, Y. Qiu, Z. H. Peng, Y. C. Zhang, Y. Alsaid, I. Frenkel, K. Youssef, Q. B. Pei and X. M. He, Matter, 2020, 3, 1196-1210.

92 Z. Ming, Y. Pang and J. Liu, Adv. Mater., 2020, 32, 1906870.

93 S. M. Hashemnejad, A. Z. M. Badruddoza, B. Zarket, C. R. Castaneda and P. S. Doyle, Nat. Commun., 2019, 10, 2749.

94 M. H. Ayoubi-Joshaghani, K. Seidi, M. Azizi, M. Jaymand, T. Javaheri, R. Jahanban-Esfahlan and M. R. Hamblin, Adv. Funct. Mater., 2020, 30, 2004098.

95 L. Z. Zhang, J. H. Liang, C. Y. Jiang, Z. H. Liu, L. J. Sun, S. Chen, H. X. Xuan, D. Lei, Q. B. Guan, X. F. Ye and Z. W. You, Natl. Sci. Rev., 2020, 8, nwaa154.

96 H. Lei, L. Dong, Y. Li, J. S. Zhang, H. Y. Chen, J. H. Wu, Y. Zhang, Q. Y. Fan, B. Xue, M. Qin, B. Chen, Y. Cao and W. Wang, Nat. Commun., 2020, 11, 4032.

97 C. Wang, P. Zhang, W. Q. Xiao, J. Q. Zhao, M. T. Shi, H. Q. Wei, Z. H. Deng, B. L. Guo, Z. J. Zheng and Y. Yu, Nat. Commun., 2020, 11, 4694.

98 S. W. Zhao, Y. Chen, B. P. Partlow, A. S. Golding, P. Tseng, J. Coburn, M. B. Applegate, J. E. Moreau, F. G. Omenetto and D. L. Kaplan, Biomaterials, 2016, 93, 60-70.

99 E. M. Pritchard, V. Normand, X. Hu, S. Budijono, D. Benczédi, F. Omenetto and D. L. Kaplan, J. Appl. Polym. Sci., 2014, 131, 596.

100 L. Tian, Y. Chen and S. J. Min, Bomed. Eng., 2007, 24, 1309-1313.

101 M. L. Floren, S. Spilimbergo, A. Motta and C. Migliaresi, Biomacromolecules, 2012, 13, 2060-2072.

102 H. Y. Zheng and B. Q. Zuo, J. Mater. Chem. B, 2021, 9, 1238-1258.

103 G. Y. Li, P. Zhou, Z. Z. Shao, X. Xie and T. Y. Yu, Eur. J. Biochem., 2001, 268, 6600-6606.

104 R. Merindol, G. Delechiave, L. Heinen, L. H. Catalani and A. Walther, Nat. Commun., 2019, 10, 528.

105 Z. H. Li, S. C. Ji, Y. Z. Wang, X. C. Shen and H. Liang, Front. Mater. Sci., 2013, 7, 237-247.

106 H. J. Jin and D. L. Kaplan, Nature, 2003, 424, 1057-1061.

107 C. Z. Zhou, F. Confalonieri, N. Medina, Y. Zivanovic, C. Esnault, T. Yang, M. Jacquet, J. Janin, M. Duguet and R. Perasso, Nucleic Acids Res., 2000, 28, 2413-2419.

108 S. Nagarkar, A. Patil, A. Lele, S. Bhat, J. Bellare and R. A. Mashelkar, Ind. Eng. Chem. Res., 2009, 48, 8014-8023.

109 Z. F. Wang, H. F. Li, Z. J. Tang, Z. X. Liu, Z. H. Ruan, L. T. Ma, Q. Yang, D. H. Wang and C. Y. Zhi, Adv. Funct. Mater., 2018, 28, 1804560.

110 A. R. Murphy and D. L. Kaplan, J. Mater. Chem., 2009, 19, 6443-6450.

111 Y. H. Guo, J. Bae, F. Zhao and G. H. Yu, Trends Chem., 2019, 1, 335-348.
112 J. G. Fernandez and D. E. Ingber, Adv. Mater., 2012, 24, 480-484.

113 Y. Gotoh, M. Tsukada, N. Minoura and Y. Imai, Biomaterials, 1997, 18, 267-271.

114 Y. Huang, X. Zhao, Z. Y. Zhang, Y. P. Liang, Z. H. Yin, B. J. Chen, L. Bai, Y. Han and B. L. Guo, Chem. Mater., 2020, 32, 6595-6610.

115 M. Liu, X. Song, Y. T. Wen, J. L. Zhu and J. Li, ACS Appl. Mater. Interfaces, 2017, 9, 35673-35682.

116 W. Q. Yang, L. L. Lv, X. K. Li, X. Han, M. J. Li and C. X. Li, ACS Nano, 2020, 14, 10600-10607.

117 L. Huang, C. Li, W. J. Yuan and G. Q. Shi, Nanoscale, 2013, 5, 3780-3786.

118 H. Y. Zheng, N. Lin, Y. Y. He and B. Q. Zuo, ACS Appl. Mater. Interfaces, 2021, 13, 40013-40031.

119 T. Li, X. B. Song, C. M. Weng, X. Wang, J. Y. Wu, L. Sun, X. Y. Gong, W. N. Zeng, L. Yang and C. Chen, Int. J. Biol. Macromol., 2018, 115, 300-307.

120 B. B. Mandal, S. Kapoor and S. C. Kundu, Biomaterials, 2009, 30, 2826-2836.

121 L. Daelemans, W. Van Paepegem, D. R. D'hooge and K. De Clerck, Adv. Funct. Mater., 2019, 29, 1807434.

122 J. F. Ming, S. Y. Bie, Z. J. Jiang, P. Wang and B. Q. Zuo, Materials Letters, 2014, 126, 169-173.

123 H. H. Kim, J. B. Park, M. J. Kang and Y. H. Park, Int. J. Biol. Macromol., 2014, 70, 516-522.

124 L. L. Hou, N. Wang, J. Wu, Z. M. Cui, L. Jiang and Y. Zhao, Adv. Funct. Mater., 2018, 28, 1801114.

125 T. Asakura, C. Tanaka, M. Y. Yang, J. Yao and M. Kurokawa, Biomaterials, 2004, 25, 617-624.

126 T. Deptuch and H. Dams-Kozlowska, Materials, 2017, 10, 1417.

127 S. H. Wang, Y. Y. Zhang, M. Y. Yang, L. P. Ye, L. Gong, Q. J. Qian, Y. J. Shuai, Z. Y. You, Y. Y. Chen and B. X. Zhong, PLoS One, 2016, 11, e0159111.

128 T. Scheibel, R. Parthasarathy, G. Sawicki, X. M. Lin, H. Jaeger and S. L. Lindquist, Proc. Natl. Acad. Sci. U. S. A., 2003, 100, 4527-4532.

129 S. G. Zhang, Nat. Biotechnol., 2003, 21, 1171-1178.

130 D. Chow, M. L. Nunalee, D. W. Lim, A. J. Simnick and A. Chilkoti, Mater. Sci. Eng., R, 2008, 62, 125-155.

131 W. W. Huang, A. Tarakanova, N. Dinjaski, Q. Wang, X. X. Xia, Y. Chen, J. Y. Wong, M. J. Buehler and D. L. Kaplan, Adv. Funct. Mater., 2016, 26, 4113-4123.

132 J. Gustafson, K. Greish, J. Frandsen, J. Cappello and H. Ghandehari, J. Controlled Release, 2009, 140, 256.

133 D. W. Urry, S. Q. Peng and T. M. Parker, Biopolymers, 1992, 32, 373-379.

134 R. Dandu, A. V. Cresce, R. Briber, P. Dowell, J. Cappello and H. Ghandehari, Polymer, 2009, 50, 366-374.

135 A. Poursaid, M. M. Jensen, I. Nourbakhsh, M. Weisenberger, J. W. Hellgeth, S. Sampath, J. Cappello and H. Ghandehari, Mol. Pharmaceut., 2016, 13, 2736-2748.

136 A. Poursaid, R. Price, A. Tiede, E. Olson, E. Huo, A. McGill, H. Ghandehari and J. Cappello, Biomaterials, 2015, 57, 142-152. 
137 A. A. Dinerman, J. Cappello, H. Ghandehari and S. W. Hoag, J. Controlled Release, 2002, 82, 277-287.

138 M. Haider, V. Leung, F. Ferrari, J. Crissman, J. Powell, J. Cappello and H. Ghandehari, Mol. Pharmaceut., 2005, 2, 139-150.

139 Y. Li, B. Xue and Y. Cao, ACS Macro Lett., 2020, 9, 512-524.

140 S. Yodmuang, S. L. McNamara, A. B. Nover, B. B. Mandal, A. Agarwal, T. N. Kelly, P. G. Chao, C. Hung, D. L. Kaplan and G. Vunjak-Novakovic, Acta Biomater., 2015, 11, 27-36.

141 F. Mirahmadi, M. Tafazzoli-Shadpour, M. A. Shokrgozar and S. Bonakdar, Mater. Sci. Eng., C, 2013, 33, 4786-4794.

142 Y. P. Singh, M. Adhikary, N. Bhardwaj, B. K. Bhunia and B. B. Mandal, Biomed. Mater., 2017, 12, 045012.

143 C. S. Lee, H. S. Hwang, S. Kim, J. Fan, T. Aghaloo and M. Lee, Adv. Funct. Mater., 2020, 30, 2003717.

144 T. Diab, E. M. Pritchard, B. A. Uhrig, J. D. Boerckel, D. L. Kaplan and R. E. Guldberg, J. Mech. Behav. Biomed. Mater., 2012, 11, 123-131.

145 L. H. Wang, Y. Y. Qiu, Y. X. Guo, Y. Si, L. F. Liu, J. P. Cao, J. Y. Yu, X. R. Li, Q. Zhang and B. Ding, Nano Lett., 2019, 19, 9112-9120.

146 S. Bose, N. Sarkar and D. Banerjee, Mater. Today Chem., 2018, 8, 110-120.

147 T. J. Long, Y. X. Li, X. Fang and J. Q. Sun, Adv. Funct. Mater., 2018, 28, 1804416.

148 W. Sun, A. Motta, Y. Shi, A. Seekamp, H. Schmidt, S. N. Gorb, C. Migliaresi and S. Fuchs, Biomed. Mater., 2016, 11, 035009.

149 B. C. Cheng, Y. F. Yan, J. J. Qi, L. F. Deng, Z. W. Shao, K. Q. Zhang, B. Li, Z. L. Sun and X. M. Li, ACS Appl. Mater. Interfaces, 2018, 10, 12474-12484.

150 B. M. Min, L. Jeong, Y. S. Nam, J. M. Kim, J. Y. Kim and W. H. Park, Int. J. Biol. Macromol., 2004, 34, 223-230.

151 I. Kalashnikova, S. Das and S. Seal, Nanomedicine, 2015, 10, 2593-2612.

152 P. S. Korrapati, K. Karthikeyan, A. Satish, V. R. Krishnaswamy, J. R. Venugopal and S. Ramakrishna, Mater. Sci. Eng., C, 2016, 67, 747-765.

153 O. Moreno-Arotzena, J. G. Meier and A. C. Del, Materials, 2015, 8, 1636-1651.

154 B. M. Min, G. Lee, S. H. Kim, Y. S. Nam, T. S. Lee and W. H. Park, Biomaterials, 2004, 25, 1289-1297.

155 J. Langer and P. Vacanti, Science, 1993, 260, 920-926.

156 J. Melke, S. Midha, S. Ghosh, K. Ito and S. Hofmann, Acta Biomater., 2016, 31, 1-16.

157 G. Tiwari, R. Tiwari, S. Bannerjee, L. Bhati, S. Pandey, P. Pandey and B. Sriwastawa, Int. J. Pharm. Investig., 2012, 2, 2-11.

158 I. Brigger, C. Dubernet and P. Couvreur, Adv. Drug Delivery Rev., 2002, 54, 631-651.

159 M. E. Byrne, K. Park and N. A. Peppas, Adv. Drug Delivery Rev., 2002, 54, 149-161.

160 P. B. Malafaya, G. A. Silva and R. L. Reis, Adv. Drug Delivery Rev., 2007, 59, 207-233.

161 F. Chiellini, A. M. Piras, C. Errico and E. Chiellini, Nanomedicine, 2008, 3, 367-393.
162 N. B. Graham and M. E. Mcneill, Hydrogels for controlled drug delivery, Palgrave Macmillan, London, 1984, pp. 27-36.

163 X. Q. Wang, B. Partlow, J. Liu, Z. Z. Zheng, B. Su, Y. S. Wang and D. L. Kaplan, Acta Biomater., 2015, 12, 51-61.

164 C. H. Park, L. Jeong, D. Cho, O. H. Kwon and W. H. Park, Carbohydr. Polym., 2013, 98, 1179-1185.

165 H. Cao, Y. H. Yang and Z. Z. Shao, J. Controlled Release, 2015, 213, e39.

166 K. Y. Liu, Z. Fan, T. J. Wang, Z. H. Gao, J. J. Zhong, G. Xiang, W. Lei, Z. F. Shi, Y. F. Feng, Y. Mao and T. H. Tao, Adv. Healthcare Mater., 2020, 9, 2000879.

167 C. B. Rodell, R. J. Wade, B. P. Purcell, N. N. Dusaj and J. A. Burdick, ACS Biomater. Sci. Eng., 2015, 1, 277-286.

168 L. Y. Shi, Y. N. Zhao, Q. F. Xie, C. X. Fan, J. Hilborn, J. W. Dai and D. A. Ossipov, Adv. Healthcare Mater., 2018, 7, 1700973.

169 V. Yesilyurt, M. J. Webber, E. A. Appel, C. Godwin, R. Langer and D. G. Anderson, Adv. Mater., 2016, 28, 86-91.

170 J. C. Hu, B. Chen, F. Guo, J. Y. Du, P. C. Gu, X. J. Lin, W. P. Yang, H. L. Zhang, M. Lu, Y. P. Huang and G. W. Xu, J. Mater. Sci. Mater. Med., 2012, 23, 711-722.

171 J. J. Qi, Y. F. Yan, B. C. Cheng, L. F. Deng, Z. W. Shao, Z. L. Sun and X. M. Li, ACS Appl. Mater. Interfaces, 2018, 10, 6180-6189.

172 L. Meng, C. Y. Shao, C. Cui, F. Xu, J. D. Lei and J. Yang, ACS Appl. Mater. Interfaces, 2020, 12, 1628-1639.

173 Z. Z. Ding, M. L. Zhou, Z. Y. Zhou, W. J. Zhang, X. Q. Jiang, X. H. Lu, B. Q. Zuo, Q. Lu and D. L. Kaplan, ACS Biomater. Sci. Eng., 2019, 5, 4077-4088.

174 D. H. Su, L. B. Jiang, X. Chen, J. Dong and Z. Z. Shao, ACS Appl. Mater. Interfaces, 2016, 8, 9619-9628.

175 N. N. Yang, P. Qi, J. Ren, H. P. Yu, S. X. Liu, J. Li, W. S. Chen, D. L. Kaplan and S. J. Ling, ACS Appl. Mater. Interfaces, 2019, 11, 23632-23638.

176 J. W. Seo, H. Kim, K. H. Kim, S. Q. Choi and H. J. Lee, Adv. Funct. Mater., 2018, 28, 1800802.

177 S. H. Jeong, S. Zhang, K. Hjort, J. Hilborn and Z. Wu, Adv. Mater., 2016, 28, 5830-5836.

178 S. Lee, Y. Inoue, D. Kim, A. Reuveny, K. Kuribara, T. Yokota, J. Reeder, M. Sekino, T. Sekitani, Y. Abe and T. Someya, Nat. Commun., 2014, 5, 5898.

179 M. Jo, K. Min, B. Roy, S. Kim, S. Lee, J. Y. Park and S. Kim, ACS Nano, 2018, 12, 5637-5645.

180 M. Ribeiro, M. A. de Moraes, M. M. Beppu, M. P. Garcia, M. H. Fernandes, F. J. Monteiro and M. P. Ferraz, Eur. Polym. J., 2015, 67, 66-77.

181 P. Dorishetty, R. Balu, A. Sreekumar, L. de Campo, J. P. Mata, N. R. Choudhury and N. K. Dutta, ACS Sustainable Chem. Eng., 2019, 7, 9257-9271.

182 M. H. Kim, B. S. Kim, J. Lee, D. Cho, O. H. Kwon and W. H. Park, Biomater. Res., 2017, 21, 12.

183 U. J. Kim, J. Park, C. M. Li, H. J. Jin, R. Valluzzi and D. L. Kaplan, Biomacromolecules, 2004, 5, 786-792.

184 L. L. Wang, D. W. Song, X. Y. Zhang, Z. Z. Ding, X. D. Kong, Q. Lu and D. L. Kaplan, ACS Biomater. Sci. Eng., 2019, 5, 613-622. 